\title{
Article \\ A Novel Finite Element Method Approach in the Modelling of Edge Trimming of CFRP Laminates
}

\author{
Fernando Cepero-Mejias ${ }^{1, *}$, Nicolas Duboust ${ }^{2}$, Vaibhav A. Phadnis ${ }^{3}$, Kevin Kerrigan ${ }^{2} \mathbb{D}$ and Jose L. Curiel-Sosa ${ }^{1}$ \\ 1 Department of Mechanical Engineering, The University of Sheffield, Sir Frederick Mappin Building, \\ Mappin Street, Sheffield S1 3JD, UK; j.curiel-sosa@sheffield.ac.uk \\ 2 Advanced Manufacturing Research Centre with Boeing, University of Sheffield, Advanced Manufacturing \\ Park, Wallis Way, Catcliff, Rotherham S60 5TZ, UK; enquiries@amrc.co.uk or n.duboust@amrc.co.uk (N.D.); \\ k.kerrigan@sheffield.ac.uk (K.K.) \\ 3 3M UK Plc, Bracknell RG12 8HT, UK; innovation.uk@mmm.com or ved.phadnis@gmail.com \\ * Correspondence: me-enquiries@sheffield.ac.uk or fmcepero1@sheffield.ac.uk; Tel.: +44-793-881-2394
}

\section{check for} updates

Citation: Cepero-Mejías, F.; Duboust, N.; Phadnis, V.A.; Kerrigan, K.; Curiel-Sosa, J.L. A Novel Finite Element Method Approach in the Modelling of Edge Trimming of CFRP Laminates. Appl. Sci. 2021, 11, 4743. https://doi.org/ 10.3390/app11114743

Academic Editors: Joao Paulo Davim, Sikiru Oluwarotimi Ismail and Redouane Zitoune

Received: 20 April 2021

Accepted: 15 May 2021

Published: 21 May 2021

Publisher's Note: MDPI stays neutral with regard to jurisdictional claims in published maps and institutional affiliations.

Copyright: (c) 2021 by the authors. Licensee MDPI, Basel, Switzerland. This article is an open access article distributed under the terms and conditions of the Creative Commons Attribution (CC BY) license (https:// creativecommons.org/licenses/by/ $4.0 /)$.

\begin{abstract}
Nowadays, the development of robust finite element models is vital to research costeffectively the optimal cutting parameters of a composite machining process. However, various factors, such as the high computational cost or the complicated nature of the interaction between the workpiece and the cutting tool significantly hinder the modelling of these types of processes. For these reasons, the numerical study of common machining operations, especially in composite machining, is still minimal. This paper presents a novel approach comprising a mixed multidirectional composite damage mode with composite edge trimming operation. An ingenious finite element framework which infer the cutting edge tool wear assessing the incremental change of the machining forces is developed. This information is essential to replace tool inserts before the tool wear could cause severe damage in the machined parts. Two unidirectional carbon fibre specimens with fibre orientations of $45^{\circ}$ and $90^{\circ}$ manufactured by pre-preg layup and cured in an autoclave were tested. Excellent machining force predictions were obtained with errors below $10 \%$ from the experimental trials. A consistent 2D FE composite damage model previously performed in composite machining was implemented to mimic the material failure during the machining process. The simulation of the spring back effect was shown to notably increase the accuracy of the numerical predictions in comparison to similar investigations. Global cutting forces simulated were analysed together with the cutting tool tooth forces to extract interesting conclusions regarding the forces received by the spindle axis and the cutting tool tooth, respectively. In general terms, vertical and normal forces steadily increase with tool wear, while tangential to the cutting tool, tooth and horizontal machining forces do not undergo a notable variation.
\end{abstract}

Keywords: machining; machining forces; finite element; modelling; edge trimming; CFRP

\section{Introduction}

Composite materials have been often used in high-performance applications because of their excellent structural capabilities such as high strength-to-weight ratio, excellent damage tolerance, or good fatigue and corrosion resistance. These advanced properties make composite components incredibly useful for highly demanding high-tech industries such as the automotive [1], the sportive [2,3], or marine applications [4], among others. The aeronautical sector, where weight reduction is a primary issue, clearly benefits the most from the use of this material. The progressive replacement of typical aluminium components in conventional designs by carbon fibre reinforced polymer (CFRP) components has achieved notable improvements in weight reduction for the aeronautical sector. For example, the implementation in the Boeing 787 of $50 \%$ of its own weight in CRFP components has achieved significant weight reductions, which lead to a considerable decrease in maintenance costs, increase fuel efficiency, and improved passenger comfort $[5,6]$. 
Although composites are manufactured in a near-net shape, subsequent machining operations are needed to guarantee the strict dimensional tolerances and surface quality demands in aerospace. Commonly, turning, drilling, and milling are the machining operations used to achieve this purpose. Turning is predominately used to adjust the dimensional tolerances of shafts. Thus, the use of cutting parameters to achieve a good surface quality is essential [7]. In general, the selection of high cutting speeds, non-wear cutting tools, and cutting the plies parallel to the fibre direction are the most significant factors to obtain a good surface quality [8,9]. Drilling is used to make bolted or riveted assemblies in composite parts. The main defects observed in this operation are the high surface delamination at the entry "push-out" and the exit "peel-up" plies caused by the high thrust forces experienced during the machining process [10-12]. Finally, milling is considered as a finishing operation to obtain high-quality surfaces in complex shapes. However, delamination and burrs with uncut fibres are often observed due to the complex interaction between the cutting tool and the laminate [13-15]. These resultant machining defects could lead to the nucleation of cracks in the surface with a drastic reduction in the fatigue life of the components [16]. Therefore, the study of the optimum machining settings to reduce or mitigate these defects has become essential to enhance the structural integrity of parts loaded in service.

Haddad et al. [17] studied the effect of cutting tool type and high speed machining parameters on the edge trimming effect of an M21 CFRP laminate. A four flute end mill was found to generate surfaces with the lowest surface roughness. Cutting temperatures which were measured using a thermal camera were found to be in the region of $80^{\circ} \mathrm{C}$ to $115^{\circ} \mathrm{C}$, below the glass transition temperature. The machining length was found to have the highest impact on cutting temperatures compared to other parameters.

Prakash et al. [18] measured acoustic emissions signals from a CFRP edge trimming process to measure the effects of cutting tool and machining parameters on surface roughness, delamination and cutting forces. Artificial neural networks have then been compared against regression model with slightly improved results. The authors found that burr style cutting tools were able to reduce delamination better than the helical shaped tools and that the mean acoustic emissions signal was found to increase with wear of the cutting tools.

Recently, Nguyen-Dinh could be consider one of the most relevant researcher in this topic. Initially, this author used new methods to assess the quality of machining using different experimental methods, scanning electron microscopy (SEM), 3D optical topography and X-ray tomography [19]. They have used areal surface roughness metrics $\left(S_{a}\right)$ and X-ray tomography to assess surface quality and crater volume $\left(C_{v}\right)$, respectively. The applied methods showed improvements in characterising damage using the Altisurf 3D non-contact scanner to take volumetric surface roughness measurements. The cutting temperature and machining induced surface roughness were both found to increase significantly with cutting distance. Low feed and high speed also significantly enhanced tool wear and cutting temperatures.

Lately, the same author [20] investigated the effect of machining parameters and tooling on harmful particles and dust which are produced during machining, measured by laser spectropic dust monitor. It was shown that a high feed speed and lower cutting speed optimised the chip thickness to increase the size of harmful dust particles, which therefore did not become as easily airborne. Additionally, machining at a $3 \mathrm{~mm}$ depth of cut compared to $2 \mathrm{~mm}$ was shown to improve the size of chip fragments and reduce the quantity of harmful particles. Three types of cutting tool were applied to find their effects on chip and dust production. It was found that the serrated straight flute tool showed some improvement in the emission of dust generated.

Finally, Nguyen-Dinh et al. [21] used new surface quality metrics crater volume and depth of damage and related these to the mechanically tested compressive behaviour of a machined CFRP laminate. These two metrics (which were measured using X-ray tomography and Altisurf techniques) have shown to be good indicators of damage; it was shown that matrix induced machining damage had a more dominating effects on material 
compressive strength than fibre dominated machining damage. The author's experiments showed that a decreasing trend in the composite compressive strength was correlated with an increasing damage depth.

Several trials are required to fully understand the effect of different cutting parameters, such as cutting speed, feed rate, helix angle, or tool wear, have on machining responses such as sub-surface damage, cutting forces, or surface quality. The complex tool/workpiece interactions, which substantially complicate the design of effective trials, in conjunction with the high cost of composites, turn experimental research into a cumbersome and expensive solution. Therefore, finite element models of composite machining that simulate the underlying physics of the problem and are experimentally validated have been proven to be an excellent cost-effective virtual alternative.

This alternative also provides detailed information on laminate failure. These failures occur mainly in the interfaces (delamination) and in the laminate constituents (fibre and matrix). These failures are essential to predict the debonding between various pieces or plies [22] as well as fibre and matrix characteristic failures in common impact or machining problems [23].

To date, most finite element (FE) investigations in composite machining have investigated orthogonal cutting operations, which shares the most relevant physical aspects of the cutting mechanism characteristic of turning operations [24]. FE orthogonal cutting investigations are focused on the study of the influence that cutting parameters have on machining responses such as cutting forces, sub-surface damage, or chip formation. A brief revision of various relevant papers in this field is collected in the following. Zenia et al. [25] found that increments in the depth of cut produce a significant increase of machining forces and damages underlying the machined surface, while rake angle variations do not significantly affect the machining responses. Wang et al. [26] concluded that, because of the high fibre bending experience in the machining of $90^{\circ}$, laminates can drastically increase the sub-surface damage in the machining of laminates with similar fibre orientations. Finally, Cepero-Mejias et al. [27] achieved, for the first time, the successful simulation of the characteristic chip fracture parallel to the fibre direction of laminates with positive fibre orientations.

Drilling modelling investigations mostly assess the impact that machining factors have on the surface delamination of the outer plies [26,28]. Phadnis et al. [29] found that the selection of high cutting speeds and low feed rates reduce the delamination levels, torque, and thrust force considerably. Later, Feito et al. [30] developed a simplified drilling FE model, which drastically reduced the computational time required for a complex drilling model in a simulation without a significant decrease in the accuracy of the predictions. The morphology of the drill bit plays a relevant role in reducing the machining-induced damage in drilling operations. For instance, Isbilir et al. [31] concluded that the use of high stage ratios in step drill bits is essential to decrease the push-out delamination. The development of more sophisticated FE models in this field have successfully studied the drilling process in more complicate composite types, such as woven or biocomposites [32,33].

In general, the FE modelling of metal milling operations has been developed in numerous investigations in recent years. However, these models still offer important limitations. For instance, the development of advanced machining friction models is required to improve the quality of feed force predictions [34]. The Johnson-Cook model is the most used to define the plastic behaviour of these metals with linear or exponential progressive damage models [35]. Many advances in this field have been achieved with these investigations. For example, Wojciechowski et al. [36] found that the cut-off transition between the burnishing regime and the chip formation regime is in a feed per tool range of 1-1.4 microns. Finally, Gao et al. [37] showed that the use of advanced modelling techniques such as the Coupled Eulerian-Lagrangian approach significantly improves the predictions quality in terms of chip shape and machining forces.

Although composite milling is one of the most common operations to achieve high-quality surface finishing in the industry, they have not been widely modelled so far. To study these 
operations, simplified FE orthogonal cutting models are implemented because of the high difficulty of simulating explicitly the characteristic material failure and chip separation of the milling process [38]. Therefore, the development of sophisticated FE models capable of solving the doubts about the physical mechanism of failure concerning composite milling is necessary for future investigations. Furthermore, the implementation of damage algorithms to mimic the characteristic progressive loss of mechanical properties and crack propagation observed in the damaged areas is vital to accomplish this matter [39].

The orientation of the cracks plays a fundamental role in the appearance of defects in the mechanical surface, such as surface roughness or sub-surface damage. A clear increase in these variables is observed in fibre orientations greater than $90^{\circ}$ due to the fact that the great bending effect causes the fibre breakage to occur in a very irregular way below the cutting surface as well as a significant increase in the fibre matrix debonding extension into the sub-surface damage [40,41].

However, the orientation of the fibres is not the only factor that influences the increase in sub-surface damage; the wear of the tool tip also contributes significantly to the increase in the length of the cracks propagating into the machined surface. The impact of blunt tool tips (large tool edge radius) interacting with the fibre tends to push the fibres, generating a significant bending effect rather than shearing them. This mechanism increases the size of the cracks produced by the fibre-matrix debonding below the machined surface, considerably reducing the structural integrity of the part [42]. Therefore, this tool wear must be quickly detected by evaluating variations in the mechanical responses. This information can be used to know when the worn tool inserts should be replaced in order to avoid the massive rejection of parts in a manufacturing production system. The most effective and easy-to-obtain indicator that shows the emergence of severe tool wear is the visualisation of an increment in the cutting forces. Therefore, the investigation of the variations of the cutting forces caused by the tool wear during machining is necessary to enhance the final structural quality of the machined components.

This paper address this matter, developing a consistent FE study of a characteristic milling operation called edge trimming to analyse the effect of tool wear on the machining forces. For this purpose, the machining of two unidirectional (UD) CFRP laminates with $45^{\circ}$ and $90^{\circ}$ fibre orientations were assessed. Tool wear was accounted for by increasing, in several simulations, the cutter tool edge radius, from $10 \mu \mathrm{m}$ to $50 \mu \mathrm{m}$. Laminate behaviour was modelled using a damage algorithm based on a hybrid Puck-Maximum stress failure criteria to determine composite damage onset and subsequently reduce the mechanical properties linearly [43]. The numerical implementation of the spring back phenomenon (partial thickness recovery of the machined surface) was found to be essential to improve the accuracy of the numerical predictions. Numerical results are validated using the experimental data collected in the trials developed by Duboust et al. [44]. Interesting conclusions from the evolution of global forces to the spindle axis $\left(F_{X}=\right.$ Horizontal force and $F_{Y}=$ Vertical force $)$ and related forces to the cutting tool tooth $\left(F_{T}=\right.$ Tangential force and $F_{N}=$ Normal force) are collected in this manuscript.

\section{Experimental Set-Up}

The milling process differs from orthogonal cutting in that there is a rotating tool with multiple cutting edges and intermittent contact of each cutting edge with the workpiece. Additionally, there is also a constantly changing thickness in the size of the removed chip as the tool is fed into the workpiece. A conventional edge trimming approach was applied in this experiment, which means that the size of the chip will increase as the tool increases engagement with the workpiece. In a composite edge trimming process, the milling kinematics mean that there will be a new fragmented chip generated for every new pass of a cutting tooth. The effect of fibre orientation also plays a role, which will change in relative orientation to the cutting edge with the rotation of the milling tool, as shown in Figure 1. 


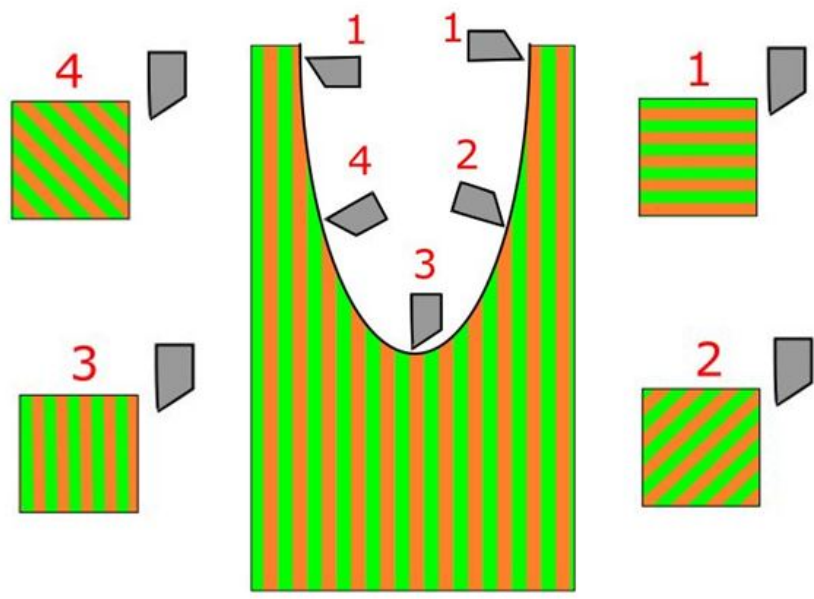

Figure 1. Relative fibre orientation change in edge trimming —orange stripes $=$ fibre, green stripes $=$ matrix .

The edge trimming machining experiments were completed on a uni-directional laminate with two different fibre orientations: $-45^{\circ}$ and $90^{\circ}$ fibre orientations. The carbon fibre laminates were manufactured by pre-preg hand layup and were cured in an autoclave. A fibre type T700G and an epoxy matrix named Hexply M21 were employed. A five axis Computer Numerical Control (CNC) machine tool, Cincinnati FTV5-2500, Cincinnati machines, Ohio (EEUU), was used to machine the carbon fibre material, see Figure 2.

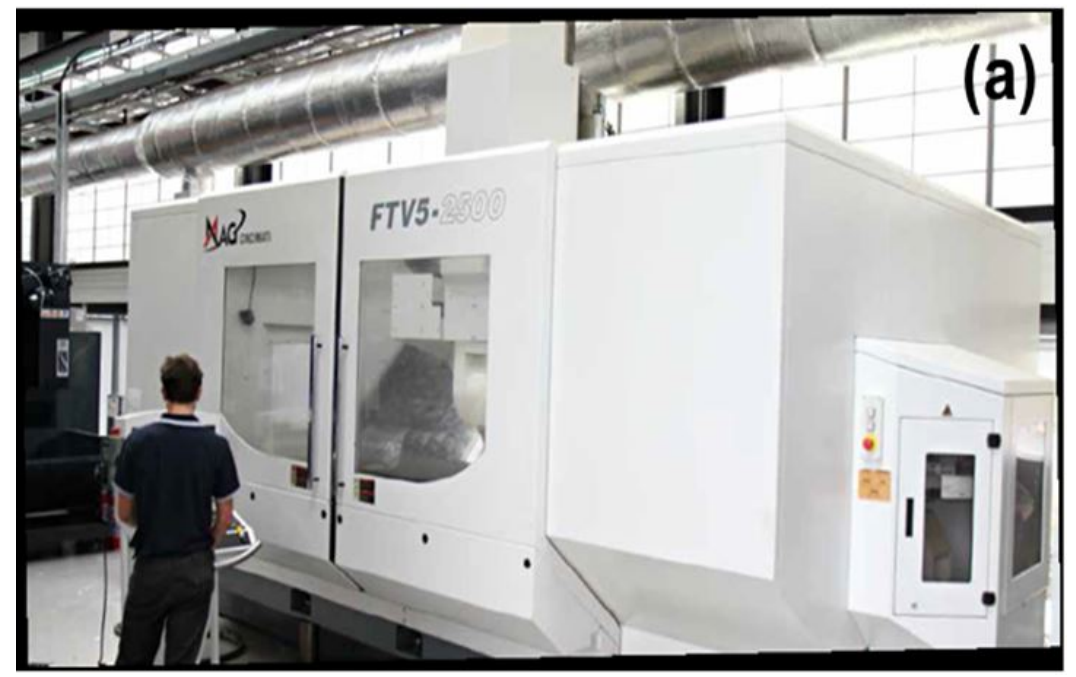

Figure 2. Five axis CNC machine tool, Cincinnati FTV5-2500.

A polycrystalline diamond (PCD) cutting tool was selected. Unidirectional CFRP laminates of 36 plies were vacuum bagged to be cured in an autoclave. The curing cycle selected is specified in the below list.

1. Apply full vacuum (1 bar).

2. Apply 7 bar gauge autoclave pressure.

3. Reduce vacuum to a safety value of -0.2 bar when the autoclave pressure reaches 1 bar gauge

4. Set heat-up rate from room temperature to $180{ }^{\circ} \mathrm{C} \pm 5^{\circ} \mathrm{C}\left(356^{\circ} \mathrm{F} \pm 9^{\circ} \mathrm{F}\right)$ to achieve an actual component heat-up rate between $1-2^{\circ} \mathrm{C} / \mathrm{min}\left(2-4{ }^{\circ} \mathrm{F} / \mathrm{min}\right)$.

5. Hold at $180{ }^{\circ} \mathrm{C} \pm 5{ }^{\circ} \mathrm{C}\left(356^{\circ} \mathrm{F} \pm 9{ }^{\circ} \mathrm{F}\right)$ for $120 \mathrm{~min} \pm 5 \mathrm{~min}$.

6. Cool component at an actual cooldown rate of $2-5^{\circ} \mathrm{C} / \mathrm{min}\left(4-9^{\circ} \mathrm{F} / \mathrm{min}\right)$.

7. Vent autoclave pressure when the component reaches $60^{\circ} \mathrm{C}\left(140{ }^{\circ} \mathrm{F}\right)$ or below. 
This laminate was cut into samples (at the required fibre orientations), which had length, width and thickness $-160 \mathrm{~mm}, 63 \mathrm{~mm}$ and $6 \mathrm{~mm}$, respectively. These samples were fixed using a clamping system as shown in Figure 3 and attached to the CNC machine tool. The cutting forces were recorded during the experiment by using a Kistler dynamometer, which was attached to the base of the CNC machine as shown in Figure 3. The effect of cutting tool wear on the machining forces was recorded by measuring the $F_{X}$ (feed force) and $F_{Y}$ (thrust force), depicted in Figure 3.
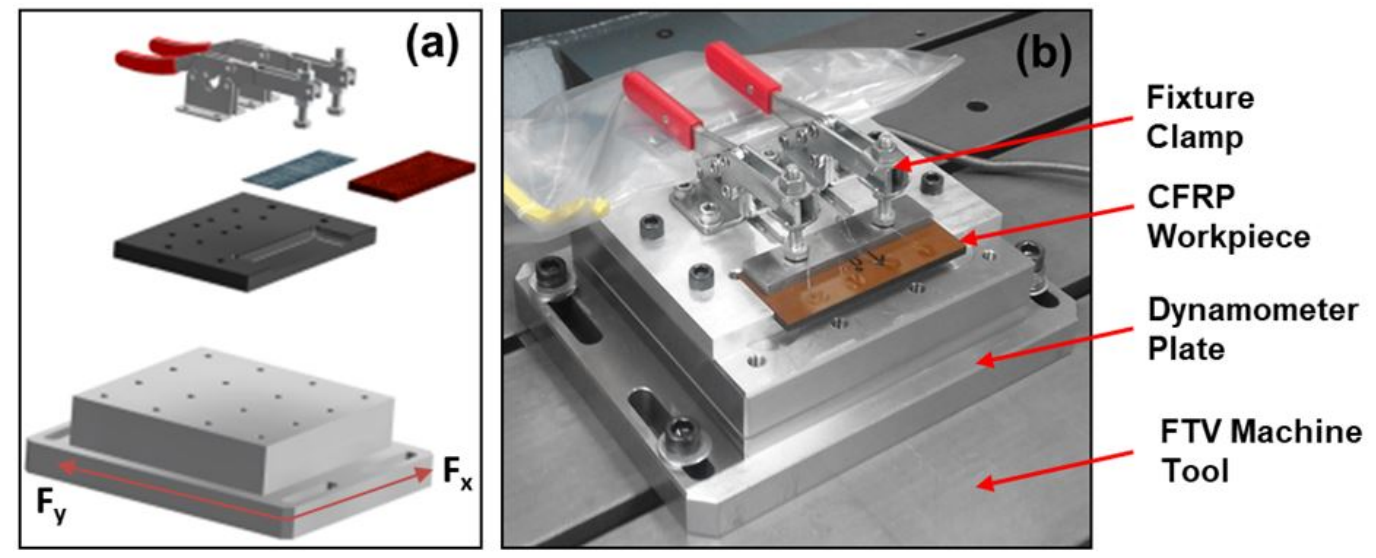

Figure 3. Edge trimming set-up: (a) separate pieces and (b) assembled set.

The mean cutting forces were calculated and compared with numerical models, which were then used to validate FE cutting simulations. The PCD cutting tool had a 0 helix angle and $10 \mathrm{~mm}$ diameter, as shown in Figure 4. Two cutting tools were used in two different conditions in new and worn condition, with a $3 \mu \mathrm{m}$ and $10 \mu \mathrm{m}$ edge radius, respectively. The tool tooth had a clearance angle of $22.4^{\circ}$, and a rake angle of $29.8^{\circ}$ with a negative $1 \mathrm{~mm}$ offset from the centre line. Each test was repeated 2 times with each cutting tool condition. The samples were cut with a full thickness axial depth of cut (ap) of $10 \mathrm{~mm}$ and a radial depth of cut of $2 \mathrm{~mm}$. A spindle speed of $6000 \mathrm{rpm}$ and $1200 \mathrm{~mm} / \mathrm{min}$ feed rate was applied using the three flute PCD cutting tool.

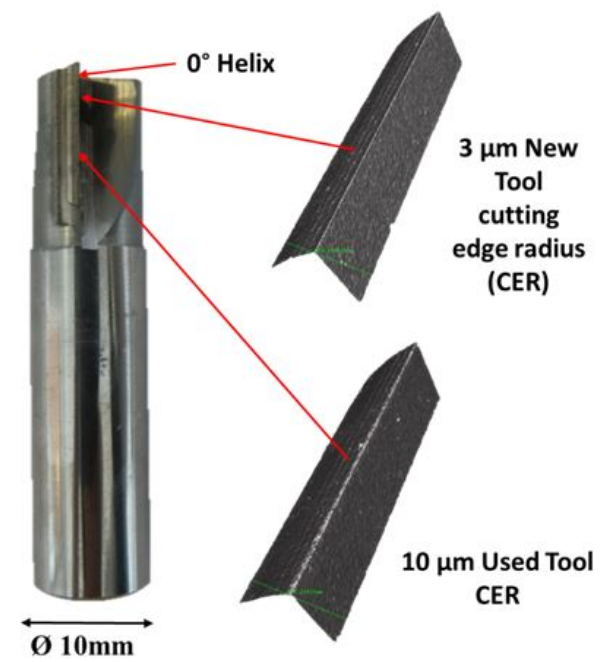

Figure 4. Three flute Polycrystalline Diamond (PCD) cutting tool with optical edge radius measurements.

\section{FE Model Characteristics}

This work focused on analysing the tool wear influence on machining forces in composite edge trimming. It was achieved by developing 2D FE plane strain simulations in Abaqus/Explicit. In the FE model, just the cutting tool teeth of the three flute, zero helix, and milling tool were 
simulated to reduce the computational cost. The initial laminate geometry was modelled to mimic the tool path when one cutting edge starts the material removal, as shown in Figure 5. CFRP mechanical and strength properties are shown in Tables 1 and 2, respectively.

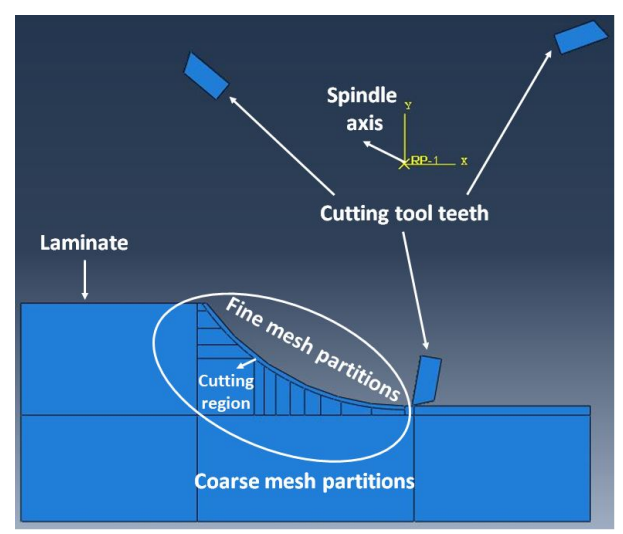

Figure 5. Mesh zoom of the closed area next to the cutter tool edge.

Table 1. CFRP mechanical properties.

\begin{tabular}{ccccc}
\hline Material & $E_{1}(\mathrm{GPa})$ & $E_{2}(\mathrm{GPa})$ & $G_{12}(\mathrm{GPa})$ & $v_{12}$ \\
\hline CFRP [44] & 148 & 7.7 & 4.7 & 0.3 \\
\hline
\end{tabular}

Table 2. CFRP strength properties.

\begin{tabular}{cccccc}
\hline Material & $X_{T}(\mathbf{M P a})$ & $X_{C}(\mathbf{M P a})$ & $Y_{T}(\mathbf{M P a})$ & $Y_{C}(\mathbf{M P a})$ & $S_{12}(\mathbf{M P a})$ \\
\hline CFRP [44] & 2375 & 1465 & 51 & 119 & 112 \\
\hline
\end{tabular}

In the above tables, $E_{11}$ and $E_{22}$ represent the composite Young modulus in directions parallel and perpendicular to the fibre, respectively. The terms $G_{12}$ and $v_{12}$ are the composite shear modulus and the Poisson's ratio, respectively. $X_{T}$ and $X_{C}$ denote the longitudinal traction and longitudinal compression laminate strengths, respectively, whereas variables $Y_{T}$ and $Y_{C}$ indicate the transversal traction and transversal compression laminate strengths, respectively. Finally, the term $S_{12}$ is the shear composite strength.

The boundary conditions were selected to reproduce the cutting condition observed in real trials reliably. The displacement at the bottom of the laminate was fixed to simulate the fixtures' clamping conditions. The horizontal displacement was restricted to zero on the lateral sides to avoid the simulated laminate bending while the cutter is in contact with the workpiece. A total of 82,376 quadrilateral CPSR4 elements were employed in this research. The mesh employed was designed to guarantee the right balance between the accuracy and the model's computational cost. The element size of $10 \mu \mathrm{m}$ in the cutting area was selected because machining forces converge around this element size; the element sizes gradually increased until achieving a maximum size of $200 \mu \mathrm{m}$ at the laminate borders. The FE model partitions and meshed distribution used in this research are illustrated in Figures 5 and 6. 


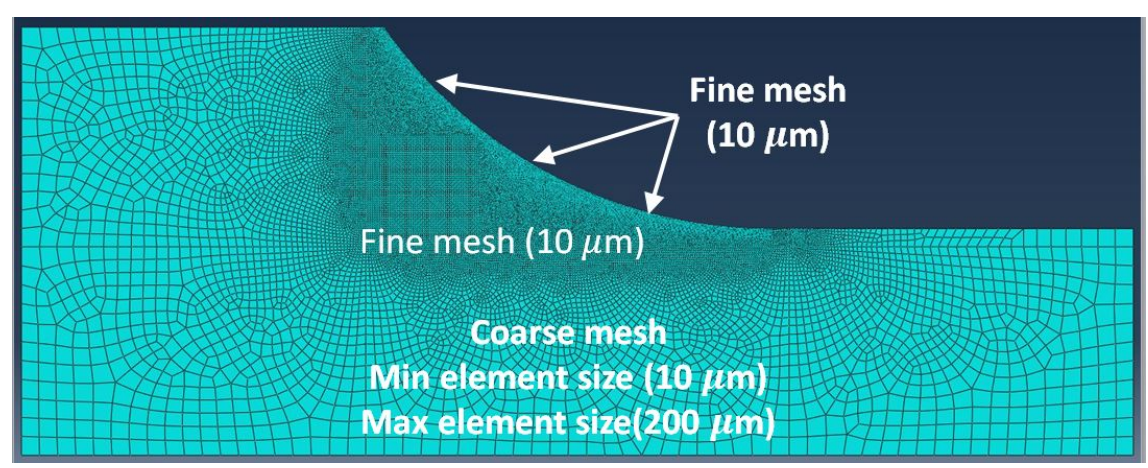

Figure 6. Meshed elements distribution in the modelled laminate.

The cutting tool was treated as a solid rigid body to reduce the FE model's computational cost. This approach is plausible because of the high rigidity and hardness of the Polycrystalline Diamond (PCD) milling tool and the low deformations levels suffered at the cutting tool tip compared to the machined composite laminate. A constant Coulomb friction coefficient of 0.1 was used to model the friction between the PCD cutter and CFRP laminates accurately [45].

\section{FEM Damage Algorithm Basics}

The composite damage model was implemented via VUMAT Fortran user-subroutine in Abaqus/Explicit. Four damage types were employed to reduce the mechanical properties linearly: (1) fibre traction, (2) fibre compression, (3) matrix traction, and (4) matrix compression. These damage types are included in the stiffness matrix to degrade the mechanical properties separately, as shown in Equation (1). The formulation of the stiffness matrix was first proposed by Lapczyk and Hurtado [46] and later applied in composite machining by Cepero-Mejias et al. [43].

$$
\left[\begin{array}{l}
\sigma_{11} \\
\sigma_{22} \\
\sigma_{12}
\end{array}\right]=\frac{1}{D}\left[\begin{array}{ccc}
\left(1-d_{f}\right) E_{11} & \left(1-d_{f}\right)\left(1-d_{m}\right) v_{21} E_{11} & 0 \\
\left(1-d_{f}\right)\left(1-d_{m}\right) v_{12} E_{22} & \left(1-d_{m}\right) E_{22} & 0 \\
0 & 0 & D\left(1-d_{s}\right) G_{12}
\end{array}\right]\left[\begin{array}{l}
\varepsilon_{11} \\
\varepsilon_{22} \\
\varepsilon_{12}
\end{array}\right]
$$

where $D=1-\left(1-d_{f}\right)\left(1-d_{m}\right) v_{12} v_{21} ; d_{s}=1-\left(1-d_{f t}\right)\left(1-d_{f c}\right)\left(1-d_{m t}\right)\left(1-d_{m c}\right)$ $d_{f}=\max \left\{d_{f t}, d_{f c}\right\} ; d_{m}=\max \left\{d_{m t}, d_{m c}\right\} ; d_{I} \epsilon[0,1]$ and $I=(f t, f c, m t, m c)$.

A hybrid composite damage algorithm was used to predict the onset of the damage modes that were studied. To determine the damage initiation in fibre damage modes, a simple maximum stress failure criteria [47] detailed in the following equations was used.

- $\quad$ Fibre traction $\left(\sigma_{11}>0\right)$

$$
F_{f t}=\frac{\sigma_{11}}{X_{T}} \geq 1
$$

- $\quad$ Fibre compression $\left(\sigma_{11}<0\right)$

$$
F_{f c}=\left|\frac{\sigma_{11}}{X_{C}}\right| \geq 1
$$

The accurate modelling of matrix damage modes is vital to predict the machining forces reliably [48]; therefore, the use of robust composite failure criteria is essential for excellent predictions. Puck's failure criterion was selected because of its high capability of determining the failure with a large number of off-axis loading scenarios [49]. For the purpose of brevity, Puck's criterion insights are not explained in detail here. This criterion is thoroughly explained in [50]. Three different matrix damage modes were distinguished: Mode A, Mode B, and Mode C. Mode A predicts matrix failure in tensile states, while Mode B and Mode $C$ were utilised to predict matrix failure in compressive loads. These damage modes are formulated below.

- $\quad$ Mode A $\left(\sigma_{22} \geq 0\right)$ 


$$
F_{m m a}=\sqrt{\left(\frac{\sigma_{12}}{R_{\perp \|}^{A}}\right)^{2}+\left(1-\frac{p_{\perp \|}^{(+)}}{R_{\perp \|}^{A}} R_{\perp}^{(+) A}\right)^{2}\left(\frac{\sigma_{22}}{R_{\perp}^{(+) A}}\right)^{2}}+\frac{p_{\perp \|}^{(+)}}{R_{\perp \|}^{A}} \sigma_{22} \geq 1
$$

- $\quad$ Mode B $\left(\sigma_{22}<0\right.$ and $\left.\sigma_{22}>-R_{\perp \perp}^{A}\right)$

$$
F_{m m b}=\sqrt{\left(\frac{\sigma_{12}}{R_{\perp \|}^{A}}\right)^{2}+\left(\frac{p}{R}\right)^{2} \sigma_{22}^{2}}+\left(\frac{p}{R}\right) \sigma_{22} \geq 1
$$

- $\quad$ Mode $C\left(\sigma_{22} \leq-R_{\perp \perp}^{A}\right)$

$$
F_{m m c}=\frac{1}{2\left[1+\left(\frac{p}{R}\right) R_{\perp \perp}^{A}\right]}\left[\left(\frac{\sigma_{12}}{R_{\perp \|}^{A}}\right)^{2}+\left(\frac{\sigma_{22}}{R_{\perp \perp}^{A}}\right)^{2}\right] \frac{R_{\perp \perp}^{A}}{-\sigma_{22}} \geq 1
$$

In the above equations, the term $F_{I}$ denotes the damage activation functions, where I is whichever of the four investigated damage modes ( $\mathrm{ft}, \mathrm{fc}, \mathrm{mt}$, and $\mathrm{mc}$ ). All terms with $R$ represent the strength components related to the fracture plane. Term $R_{\perp}^{(+) A}$ is generally associated to the transverse matrix traction strength $\left(Y_{T}\right), R_{\perp \|}^{A}$ is considered the composite shear strength $\left(S_{12}\right) . R_{\perp \perp}^{A}$ represents the transverse/transverse shear strength. In general terms, an accurate measurement of this variable presents a cumbersome venture. Therefore, this variable is usually inferred from Equation (7). Term $p_{\perp \|}^{(+)}$denotes the Puck failure envelope slope of positive matrix stresses $\left(\sigma_{22}>0\right)$ when $\sigma_{22}=0$. Finally, the value of the expression $\left(\frac{p}{R}\right)$ is extracted using the Equation (8).

$$
\begin{gathered}
R_{\perp \perp}^{A}=\frac{Y_{C}}{2\left(1+p_{\perp \perp}^{(-)}\right)} \\
\left(\frac{p}{R}\right)=\frac{p_{\perp \|}^{(-)}}{R_{\perp \|}^{A}}
\end{gathered}
$$

Subsequently, a linear energy-based softening is applied to mimic the loss of mechanical properties that each damaged area experiences. This softening has been previously used in previous investigations by these authors [43]. To reduce the mesh size sensitivity, the crack band theory is used [51]. In this theory, the stress and displacement are recalculated, accounting for the characteristic element length, which are renamed as equivalent stress $\left(\sigma_{e q}\right)$ and equivalent displacement $\left(\delta_{e q}\right)$, respectively. This action minimises the strain localisation problems to slow down the decrease of energy dissipated in refinement meshes. This damage evolution is calculated with the use of these equivalent displacements as follows,

$$
d_{I}=\frac{\delta_{I, e q}^{f}\left(\delta_{I, e q}-\delta_{I, e q}^{0}\right)}{\delta_{I, e q}\left(\delta_{I, e q}^{f}-\delta_{I, e q}^{0}\right)} \quad\left(d_{I} \in[0,1] \text { and } I=(f t, f c, m t, m c)\right)
$$

where the terms $\delta_{I, e q}^{f}$ and $\delta_{I, e q}^{0}$ represent the final and initial equivalent displacements, respectively. As can be seen in Equations (10) and (11), both terms depends on the critical fracture energy of the studied failure mode $\left(G_{I}^{c}\right)$. This fact allows the dissipation of all this fracture energy when the element damage $d_{I}$ reaches a value of 1 . In this work, the critical fracture energies used by Zhang et al. [52] were used, see Table 3. 
Table 3. Critical fracture toughnesses of the studied damage modes extracted from [52].

\begin{tabular}{ccccc}
\hline N/mm & $G_{f t}^{c}$ & $G_{f \boldsymbol{c}}^{c}$ & $G_{\boldsymbol{m} \boldsymbol{t}}^{c}$ & $G_{\boldsymbol{m c}}^{c}$ \\
\hline Critical fracture toughness & 10 & 10 & 1 & 1 \\
\hline & $\delta_{I, e q}^{f}=\frac{2 G_{I}^{c} F_{I}}{\sigma_{I, e q}^{0}}$ & & & \\
& $\delta_{I, e q}^{0}=\frac{\delta_{I, e q}}{F_{I}}$ & &
\end{tabular}

For the $90^{\circ}$ laminate, a maximum of $95 \%$ of reduction of mechanical properties in matrix damage modes $\left(d_{m}\right)$ was permitted, whereas in the shear component of the stiffness $\left(d_{s}\right)$, the maximum degradation allowed was $80 \%$. In the case of the $45^{\circ}$ laminate, both features were degraded to a $50 \%$ of their initial stiffness. These limitations in the damage reduction were implemented to mitigate the distortional problems that occur to elements when their stiffness is close to zero [53]. We would like to note that the characteristic hardening of matrix stiffness in high strain rates scenarios is not considered in this research. Hence, this variable should be included in further investigations to emulate the behaviour of the material to increase the quality of the numerical predictions.

The chip separation is also not studied in detail in this manuscript. In order to remove the machined material, a strict strain based criteria was chosen. All elements are removed when the element strain achieves a value higher of 1.2 in one of its components $\left(\varepsilon_{11}, \varepsilon_{22}\right.$ and $\varepsilon_{12}$ ). This value exceeds 100 times the order of magnitude of the strain levels required for an epoxy matrix to fail [54]. Nevertheless, it is maintained because the element erosion produces, in a discrete model, a total contact loss with the cutting tool. This fact significantly reduces the forces that the cutting tool received because an important area in contact with the cutting tool is drastically removed. This factor significantly decreases the accuracy of the prediction of machining forces because the forces coming from the spring back phenomenon are not accounted for [43]. Therefore, this element deletion criterion was used in this research to simulate these spring back forces.

Finally, all the constitutive damage model phases described in this section is represented in Figure 7.

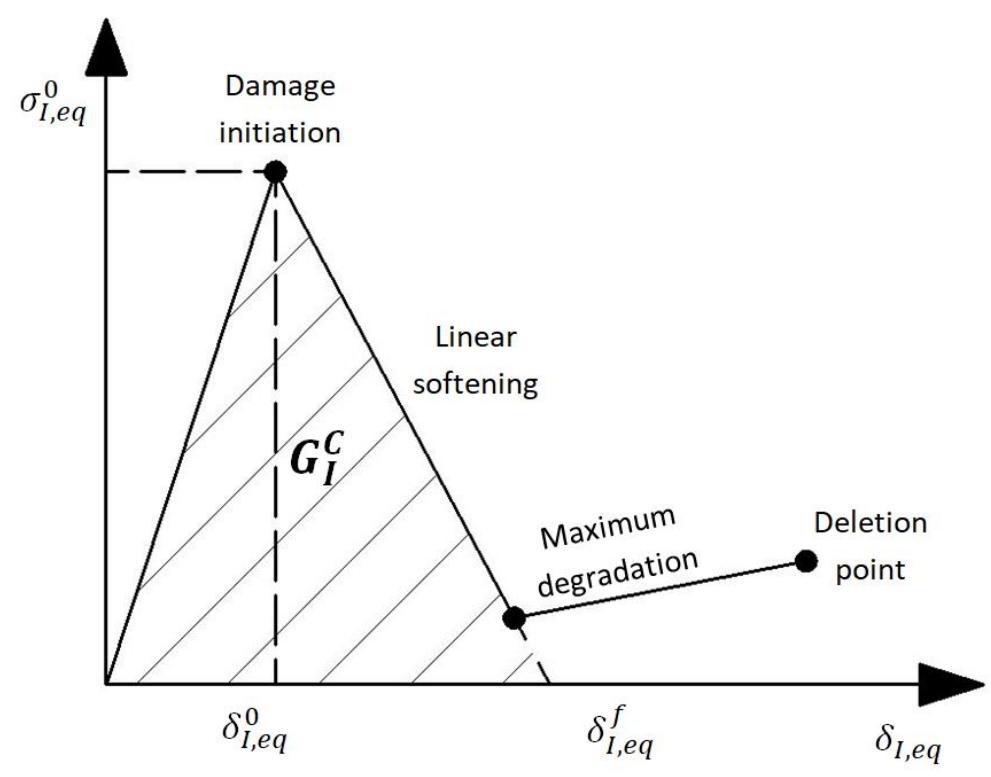

Figure 7. Constitutive damage model developed in this research. 


\section{Results and Discussion}

The cutting mechanism notably varies with tool wear, as shown in Figure 8. A new tool cut the laminate shearing small chips away. In order to model this problem, the fibre and matrix fracture mechanism should be included in the model to achieve a good quality in the numerical results. However, this configuration was not studied in this manuscript because this matter is out of the scope of this research.

A worn tool edge radius considerably reduces its effectiveness to cut fibres. As a result, the tool edge removes the material due to the high rubbing forces with the laminate, as shown in Figure 8. The increment of tool/workpiece contact area increases abruptly the ploughing forces and sub-surface damage. The proposed FE model takes into account this phenomenon and check how the cutting forces increase because of the tool wear. These results can be employed in a real test to check the tool wear, analysing the machining forces. Therefore, the inserts can be replaced before the worn edges induce excessive laminate damage.

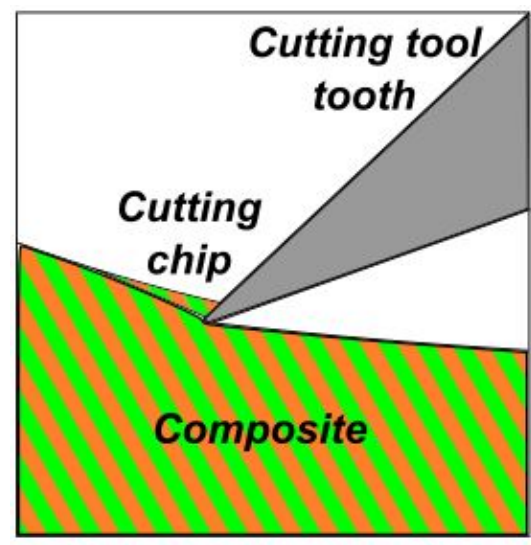

(a)

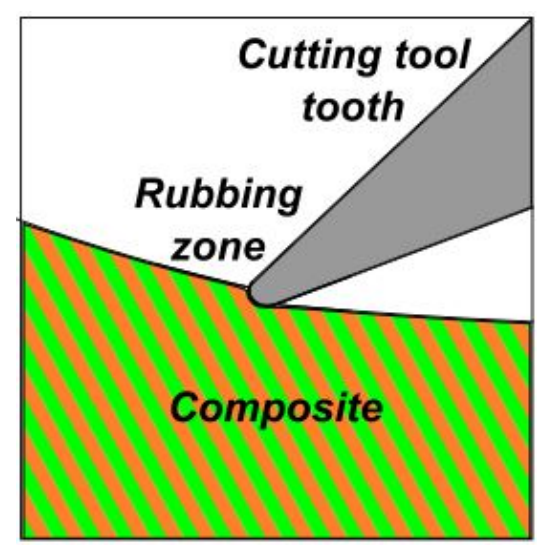

(b)

Figure 8. Representation of the characteristic edge trimming cutting mechanisms using a (a) new tool and (b) worn tool.

The simulations focus on the study of the action of the tool teeth on the material. Therefore, the simulation time selected was the time it takes for one of the tool teeth to be in contact with the laminate. A feed rate $\left(f_{r}\right)$ of $1200 \mathrm{~mm} / \mathrm{min}$, spindle speed $(w)$ of $6000 \mathrm{rpm}$, and a radial depth of cut of $2 \mathrm{~mm}$ were modelled in this research. Five cutting edges, with a radius of $10 \mu \mathrm{m}, 20 \mu \mathrm{m}, 30 \mu \mathrm{m}, 40 \mu \mathrm{m}$, and $50 \mu \mathrm{m}$, were investigated to assess the tool wear influence on the machining forces. Four distinct machining forces were analysed $F_{X}, F_{Y}, F_{T}$, and $F_{N}$, which are represented in Figure 9. $F_{X}$ and $F_{Y}$ denotes the horizontal and vertical forces, respectively. These variables allow us to analyse the machining forces experienced by the cutting tool in the spindle axis. In the case of $F_{T}$ and $F_{N}$, they are the tangent and normal forces to the cutting tool edge trajectory, respectively. Henceforth, $F_{T}$ is named tangent force and $F_{N}$ corresponds to the normal force for the purpose of clarity. These variables reliably represent the forces that the tool tooth undergoes during the machining process.

In the above figure, $\theta$ represents the angle between the line that connects the tip and the rotational centre of the cutter and the horizontal axis. Variables $w, f_{r}$, and $R$ denote the cutting speed, feed rate, and radius of the cutting tool, respectively. $V_{t}$ is the tangent velocity of the tip of the cutting tooth in contact with the laminate. Finally, $\beta$ and $\alpha$ correspond to the angles that indicate the orientation of $V_{t}$ and the coordinate system to analyse $F_{t}$ and $F_{n}$ with respect to the global coordinate system, respectively.

To transfer the machining forces obtained in the global coordinates $F_{x}$ and $F_{y}$ to the relative coordinates $F_{t}$ and $F_{n}$, it is necessary to develop a vector base change. For this purpose, the angle that forms the tangent velocity at the tool tip $\left(V_{t}\right)$ with the horizontal axis of the coordinate system $(\beta)$ is calculated. The angle between the two vector bases $(\alpha)$ is established then to transfer the forces obtained in the global coordinate system to 
the new coordinate axes. The relevant equations to complete the change of vector base are set out below.

$$
\begin{gathered}
\beta=\operatorname{atan}\left(\frac{-w R \cos \left(\theta_{0}-w t\right)}{w R \sin \left(\theta_{0}-w t\right)-20}\right)+\pi \quad \alpha=|\beta-\pi|=\left|\operatorname{atan}\left(\frac{-w R \cos \left(\theta_{0}-w t\right)}{w R \sin \left(\theta_{0}-w t\right)-20}\right)\right| \\
F_{T}=F_{X} \cos (\alpha)-F_{Y} \sin (\alpha) \\
F_{N}=F_{X} \sin (\alpha)+F_{Y} \cos (\alpha)
\end{gathered}
$$

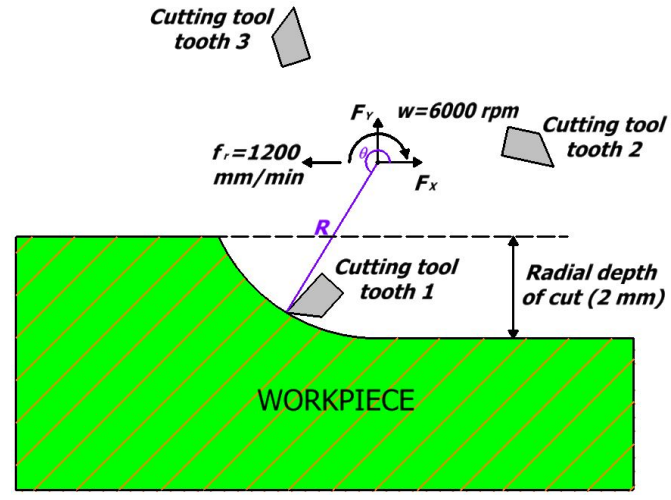

(a)

\section{Cutting tool tooth 1}

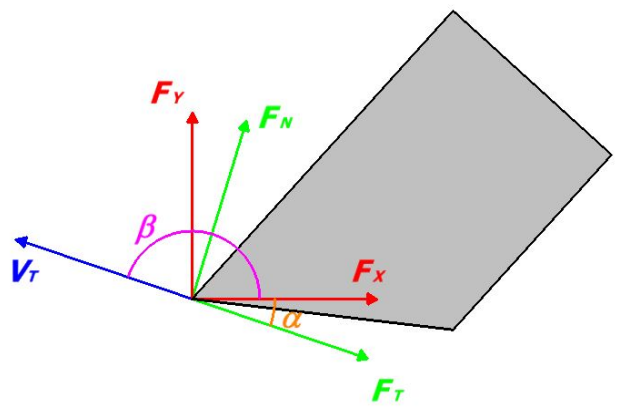

(b)

Figure 9. Representation of relevant machining parameters analysed: (a) FE model machining parameters and $(\mathbf{b})$ tool tooth forces.

In this work, the spring back phenomenon, which is the partial thickness recovery after the cutter travels through the machined surface, is included. The insertion of this phenomenon in simulations was achieved, avoiding the deletion of the elements in contact with the cutting tool edge. The interaction between the laminate and the cutting tool was observed to displace the tool tooth to the workpiece surface, as shown in. This interaction inserts new forces not accounted for in previous studies, which improves the reliability of the predictions obtained as discussed below.

Another relevant factor that influences the results is the machining relative angle. This factor is the angle between the tangent velocity of the cutting tool tip and the fibre orientation. Along with the advance of the cutting tool tooth, this angle is progressively reduced, notably influencing the machining forces obtained. For $45^{\circ}$ laminates, the machining relative angle drops from $45^{\circ}$ to $-15^{\circ}$, whereas the $90^{\circ}$ laminates go from $90^{\circ}$ to $30^{\circ}$, as shown in Figure 10. 


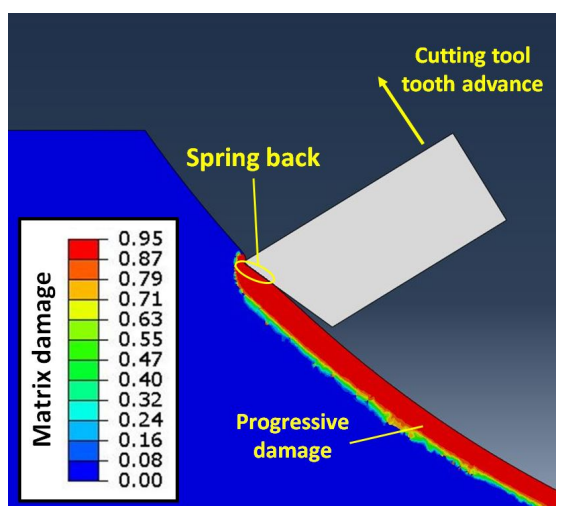

(a)

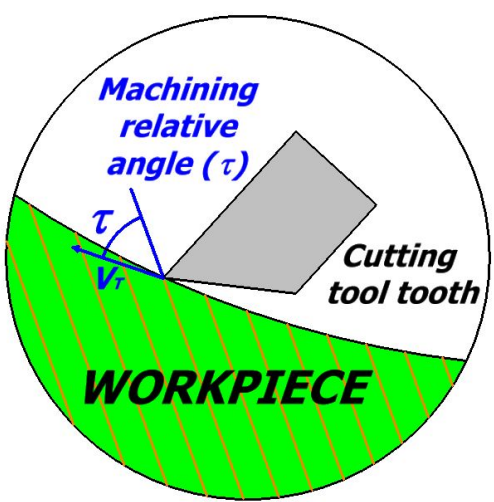

(b)

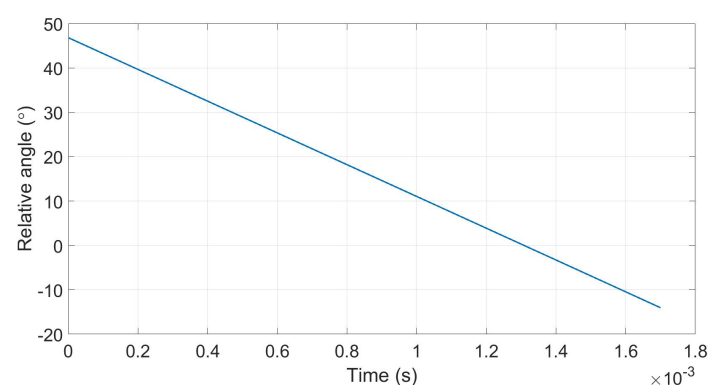

(c)

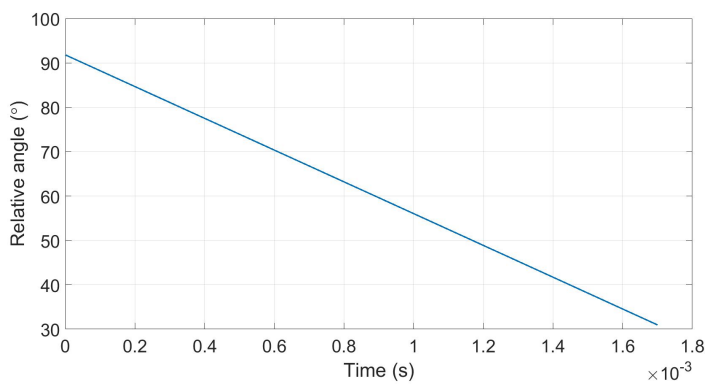

(d)

Figure 10. Representation of relevant machining parameters analysed: (a) spring back phenomenon (b) machining relative angle, (c) machining relative angle distribution for $45^{\circ}$ laminates and (d) machining relative angle distribution for $90^{\circ}$ laminates.

\subsection{Numerical FE Model Validation}

For the validation of this model, the average force data provided in the research of Duboust et al. [44] were used. All the machining configurations tested in the machining trials developed by Duboust et al. [44] with a cutting tool edge radius of $10 \mu \mathrm{m}$ were simulated. In total, eight simulations with feed rates of $800 \mathrm{~mm} / \mathrm{min}$ and $1200 \mathrm{~mm} / \mathrm{min}$, spindle speeds of $6000 \mathrm{rpm}$ and $8000 \mathrm{rpm}$, and fibre orientations of $45^{\circ}$ and $90^{\circ}$ were performed. The inclusion of the spring back phenomenon, together with the limitation in the damage of shear and matrix applied, can simulate trends in machining forces very similar to those obtained experimentally. Finally, a definite improvement was found when compared to the predictions made by Duboust et al. [44], as shown in Figures 11-14. 


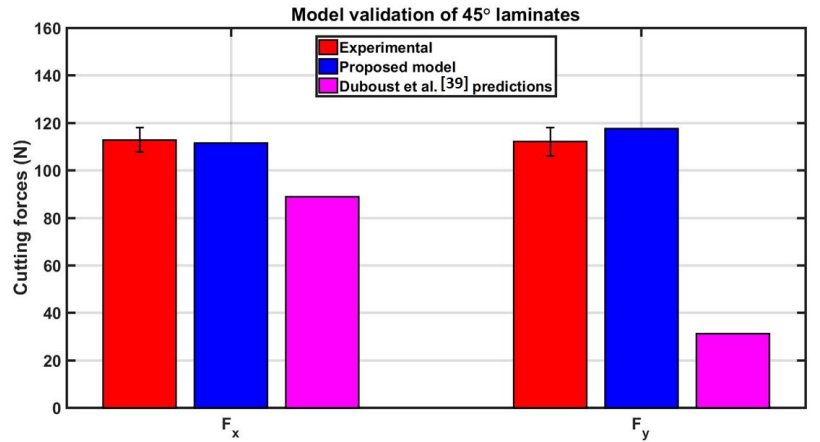

(a)

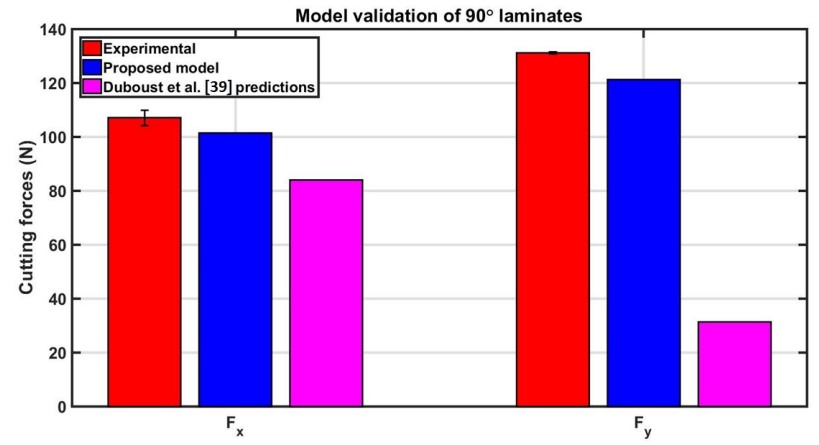

(b)

Figure 11. Validation of FE predictions with $f_{r}=800 \mathrm{~mm} / \mathrm{min}, w=6000 \mathrm{rpm}$, and fibre orientation of (a) $45^{\circ}$ and (b) $90^{\circ}$.

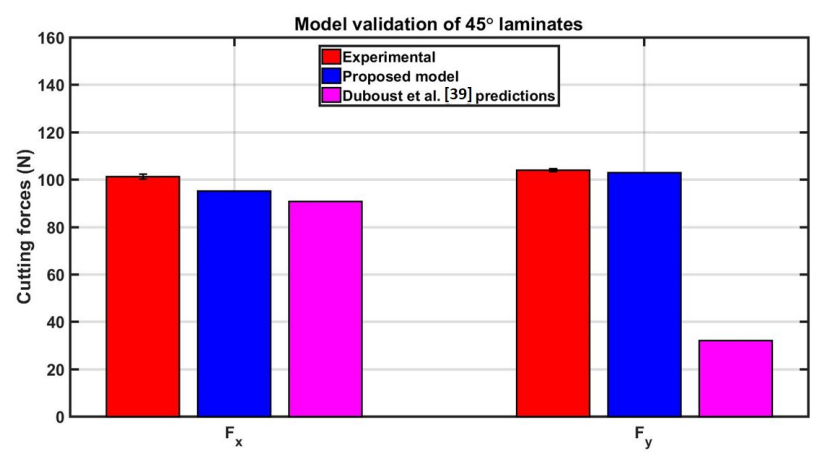

(a)

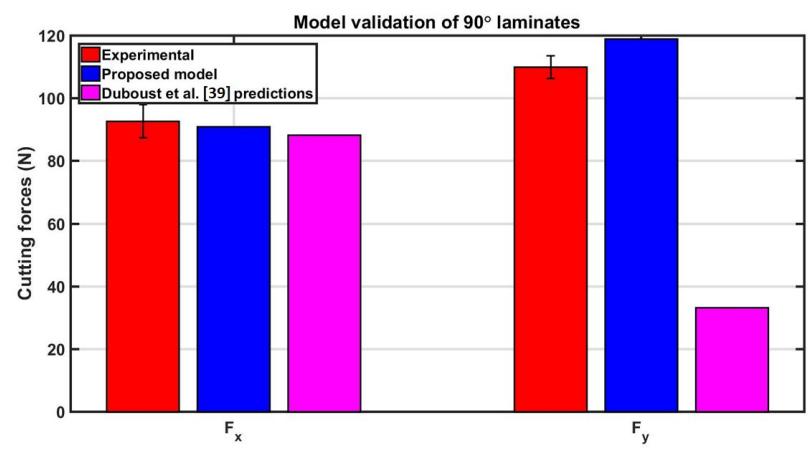

(b)

Figure 12. Validation of FE predictions with $f_{r}=800 \mathrm{~mm} / \mathrm{min}, w=8000 \mathrm{rpm}$, and fibre orientation of (a) $45^{\circ}$ and (b) $90^{\circ}$. 


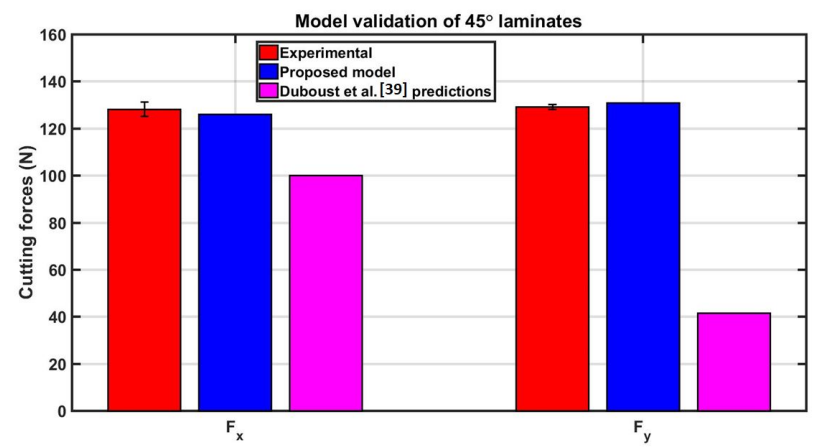

(a)

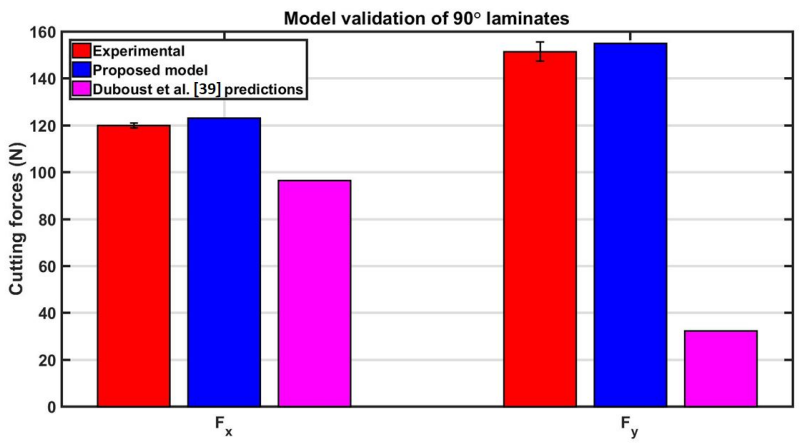

(b)

Figure 13. Validation of FE predictions with $f_{r}=1200 \mathrm{~mm} / \mathrm{min}, w=6000 \mathrm{rpm}$, and fibre orientation of (a) $45^{\circ}$ and (b) $90^{\circ}$.

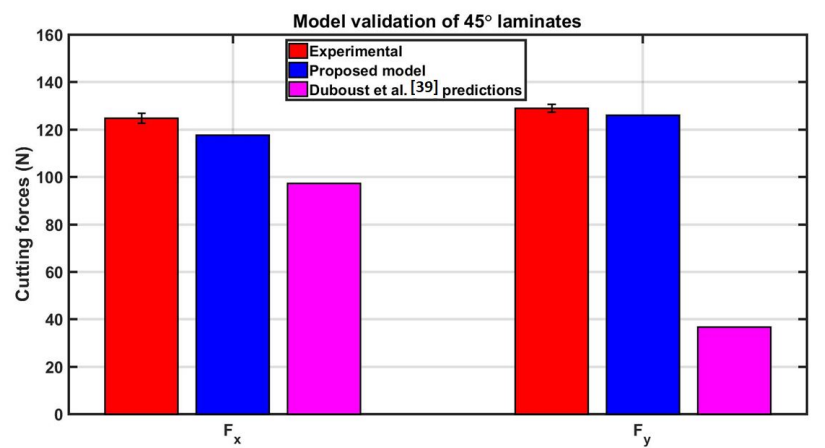

(a)

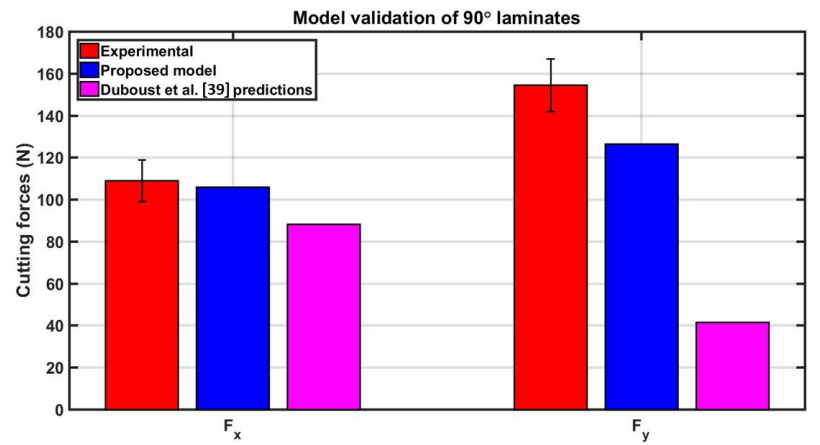

(b)

Figure 14. Validation of FE predictions with $f_{r}=1200 \mathrm{~mm} / \mathrm{min}, w=8000 \mathrm{rpm}$, and fibre orientation of (a) $45^{\circ}$ and (b) $90^{\circ}$.

The small error percentages simulated show the reliability of this FE model in predicting accurate machining forces in any cutting configuration. These errors do not exceed 10\% 
in most of the average forces simulated, as shown in Table 4. Only the configuration with $f_{r}=1200 \mathrm{~mm} / \mathrm{min}, w=8000 \mathrm{rpm}$, and $90^{\circ}$ obtained an error higher than $10 \%$ in $F_{Y}$ forces. However, a glance to Figure 14 reveals that the standard deviation calculated for these trials is considerably bigger than the standard deviation obtained in the rest of the trials. Furthermore, the model predicts a similar trend observed in the experimental findings for $F_{X}$ and $F_{Y}$ forces. From these factors it is concluded that a small error in the measurements of these forces could be the cause of this discrepancy.

Table 4. Numerical errors obtained with respect to the experimental average forces measured by Duboust et al. [44].

\begin{tabular}{|c|c|c|c|c|}
\hline Parameters & Average $F_{X} 45^{\circ}$ & Average $F_{Y} 45^{\circ}$ & Average $F_{X} 90^{\circ}$ & Average $F_{Y} 90^{\circ}$ \\
\hline$f_{r}=800 \mathrm{~mm} / \mathrm{min} w=6000 \mathrm{rpm}$ & $1.1 \%$ & $5.03 \%$ & $5.19 \%$ & $7.58 \%$ \\
\hline$f_{r}=800 \mathrm{~mm} / \mathrm{min} w=8000 \mathrm{rpm}$ & $5.98 \%$ & $0.98 \%$ & $1.87 \%$ & $8.18 \%$ \\
\hline$f_{r}=1200 \mathrm{~mm} / \mathrm{min} w=6000 \mathrm{rpm}$ & $1.61 \%$ & $1.31 \%$ & $2.64 \%$ & $2.34 \%$ \\
\hline$f_{r}=1200 \mathrm{~mm} / \mathrm{min} w=8000 \mathrm{rpm}$ & $5.67 \%$ & $2.30 \%$ & $2.97 \%$ & $18.23 \%$ \\
\hline
\end{tabular}

\subsection{Fibre Orientation of $45^{\circ}$}

Initially, the vertical forces $F_{Y}$ experience a steady growth mainly motivated by the spring back phenomenon. This takes place because the range of machining relative angles given in the edge trimming of $45^{\circ}$ laminates, from $45^{\circ}$ to $-15^{\circ}$, generate similar thrust forces in machining [55]. A parabolic decrease of the forces was observed because the spring back forces have a larger contribution to the $X$ axis, which decreases notably the quantity measured in the vertical component. Horizontal forces $F_{X}$ experience a parabolic increase due to the contribution of the spring back phenomenon to the horizontal axis. An analysis of this result reveals that cutting forces are not important in comparison to spring back forces, which are the leading cause of the $F_{X}$ and $F_{Y}$ force distribution. The global machining forces simulated for cutting tool edge radius of $10 \mu \mathrm{m}, 20 \mu \mathrm{m}, 40 \mu \mathrm{m}$, and $50 \mu \mathrm{m}$ are presented in Figure 15.

Note that the cutting forces recorded in the simulations do not follow a smooth distribution with the advancement of the tool, but rather an irregular distribution full of saw teeth. These fluctuations are explained due to the changes in the normal contact stiffness between the cutting tool and the laminate that occurs when the tool comes into contact with the different elements of the meshed laminate. When the cutting tool tip contacts with a new element, there is a slight rebound in the contact forces because of the fast increment of the contact rigidity that progressively diminishes as the tool advances its truck over the aforementioned element, as shown in Figure 16. The magnitude of these fluctuations increase notably with the implementation of higher contact stiffness and could create element distortion problems with the use of high values. In this research, a linear contact rigidity of $10 \mathrm{GPa}$ was employed to avoid this problem.

Regarding the forces $F_{T}$ and $F_{N}$, two steady rises with distinct slopes were observed. Therefore, it is concluded that the variation of the effect of the changes in machining relative angles is not crucial for this configuration. As discussed above, it was observed that spring back forces, which are responsible for the increment of $F_{N}$ forces, are higher than the cutting forces that govern the $F_{T}$ forces evolution. The representation of all graphs measuring these forces is showcased in Figure 17. 


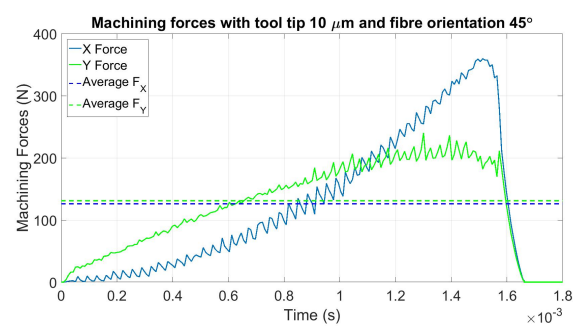

(a)

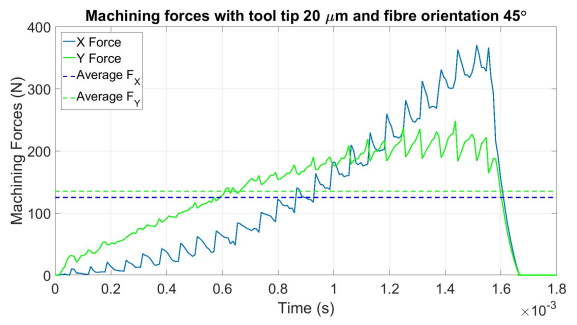

(b)

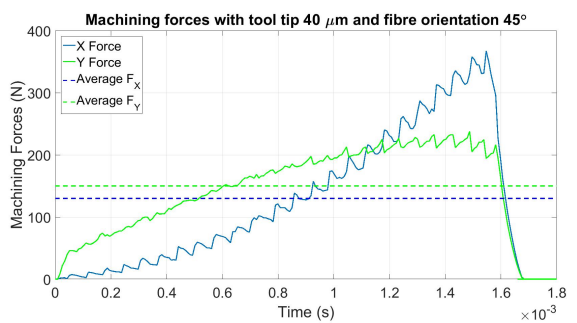

(c)

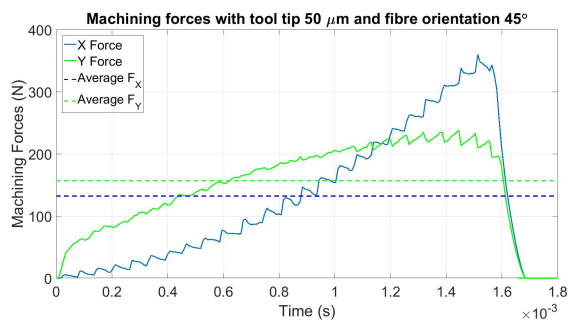

(d)

Figure 15. $F_{X}$ and $F_{Y}$ forces simulated in laminates with a fibre orientation of $90^{\circ}$ and tool edge radius of (a) $10 \mu \mathrm{m}$, (b) $20 \mu \mathrm{m}$, (c) $40 \mu \mathrm{m}$, and (d) $50 \mu \mathrm{m}$.

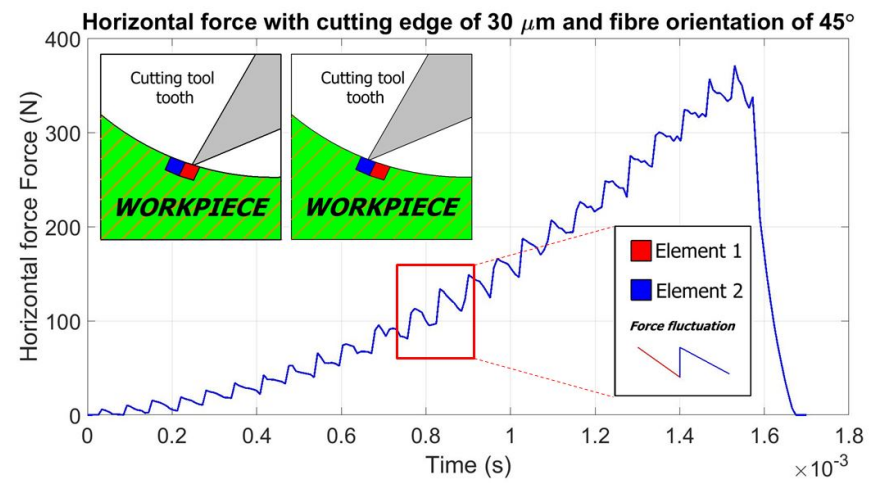

Figure 16. Horizontal force fluctuations simulated in a cutting tool edge of $30 \mu \mathrm{m}$ and a fibre orientation of $45^{\circ}$. 


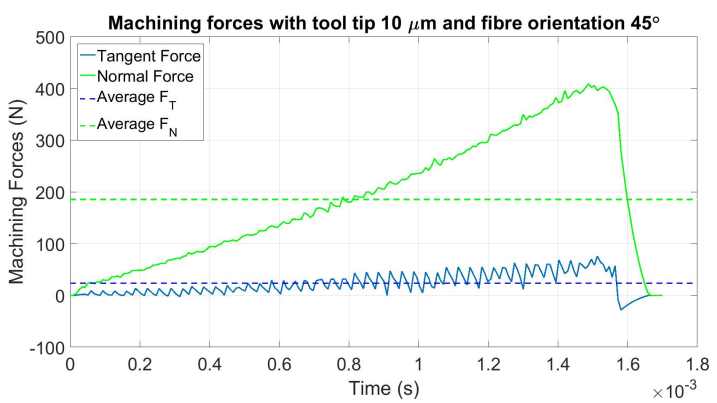

(a)

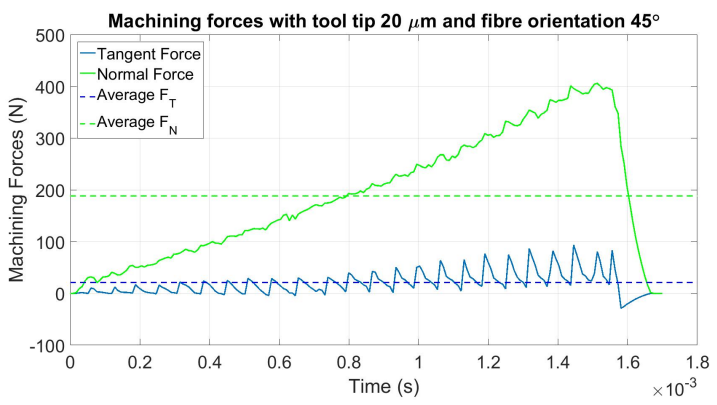

(b)

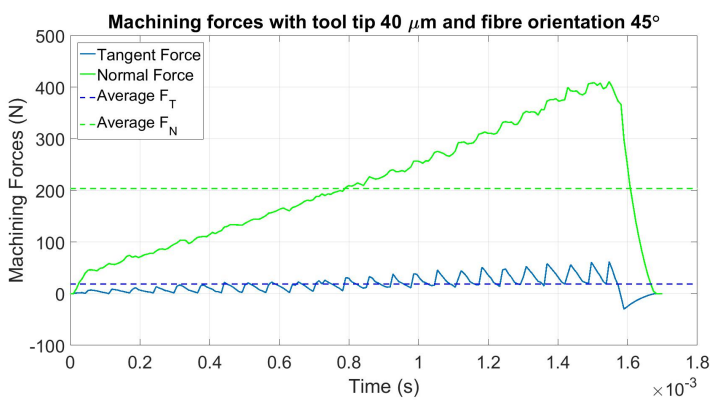

(c)

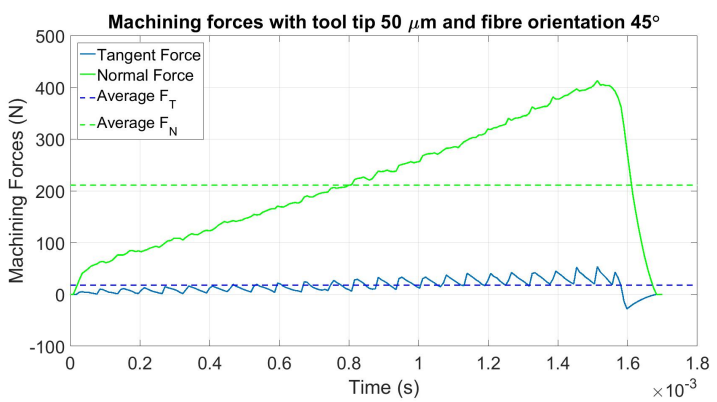

(d)

Figure 17. $F_{T}$ and $F_{N}$ forces simulated in laminates with a fibre orientation of $45^{\circ}$ and tool edge radius of (a) $10 \mu \mathrm{m}$, (b) $20 \mu \mathrm{m}$, (c) $40 \mu \mathrm{m}$, and (d) $50 \mu \mathrm{m}$.

From the analysis of the results, it is inferred that tool wear does not increase significantly (less than 20\%) the machining forces in the edge trimming of $45^{\circ}$ laminates. The most significant increments are observed in forces $F_{N}$ and $F_{Y}$ with maximum rises of $19.90 \%$ and $13.76 \%$, respectively. The force $F_{X}$ keeps stable with small increments below $5 \%$. Finally, forces $F_{T}$ are calculated to be low in comparison to the other forces analysed, as they experience a tight decrease from $23.63 \mathrm{~N}$ to $17.78 \mathrm{~N}$. The average machining forces simulated in this work are presented in Figure 18, whereas the force increments obtained with respect to the unworn cutting tool, with a tool edge radius of $10 \mu \mathrm{m}$, are shown in Table 5. 
Table 5. Average forces and increment percentage because of the tool wear simulated.

\begin{tabular}{ccccc}
\hline Tool Edge Radius & Average $\boldsymbol{F}_{\boldsymbol{X}}(\boldsymbol{N})$ & Average $\boldsymbol{F}_{\boldsymbol{Y}}(\boldsymbol{N})$ & Average $\boldsymbol{F}_{\boldsymbol{T}}(\boldsymbol{N})$ & Average $\boldsymbol{F}_{\boldsymbol{N}}(\boldsymbol{N})$ \\
\hline $10 \mu \mathrm{m}$ & $126.13(-\%)$ & $130.89(-\%)$ & $23.63(-\%)$ & $185.43(-\%)$ \\
$20 \mu \mathrm{m}$ & $124.97(-0.91 \%)$ & $134.95(3.09 \%)$ & $20.98(-11.18 \%)$ & $188.06(1.41 \%)$ \\
$30 \mu \mathrm{m}$ & $127.81(1.33 \%)$ & $143.27(9.45 \%)$ & $19.33(-18.19 \%)$ & $196.82(6.14 \%)$ \\
$40 \mu \mathrm{m}$ & $129.86(2.96 \%)$ & $150.02(14.61 \%)$ & $18.68(-20.93 \%)$ & $203.63(9.81 \%)$ \\
$50 \mu \mathrm{m}$ & $132.12(4.75 \%)$ & $156.94(19.90 \%)$ & $17.78(-24.73 \%)$ & $210.95(13.76 \%)$ \\
\hline
\end{tabular}

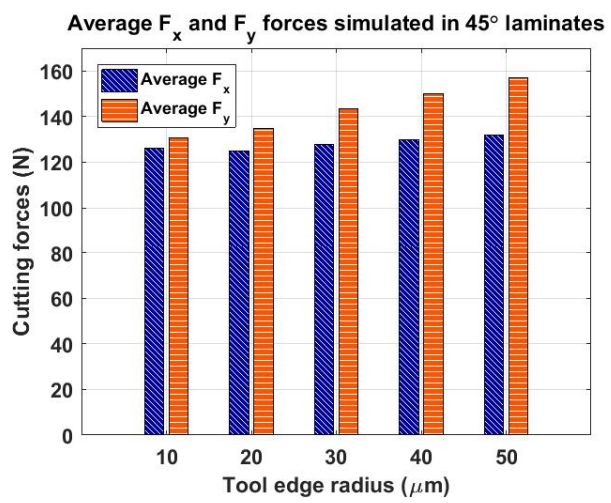

(a)

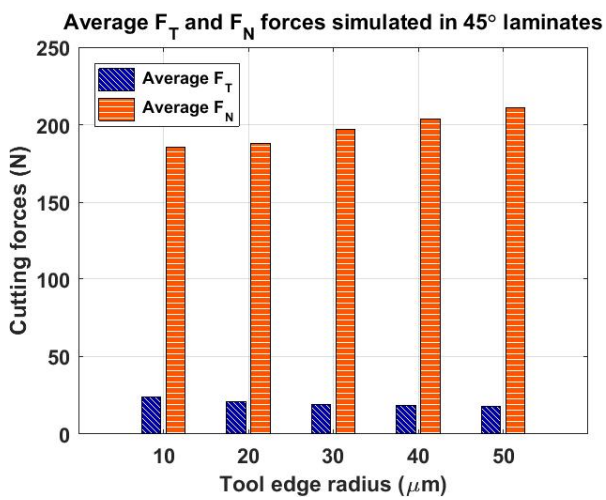

(b)

Figure 18. Representation of the average machining foces simulated with a fibre orientation of $45^{\circ}$ : (a) $F_{X}$ and $F_{Y}(\mathbf{b}) F_{T}$ and $F_{N}$.

\subsection{Fibre Orientation of $90^{\circ}$}

An observation of the vertical forces obtained reveals that these initially undergo a steep rise due to the effect of the spring back that pushes the cutting tool in the normal direction to the machined surface. This steep rise slope occurs because of the cutting tool being initially pushed with the characteristic high rigidity of laminates that are loaded parallel to the fibre. After this sharp rise, there is a decrease in the slope of this curve until it reaches a significant drop attributable to two factors. The first factor that causes this drop is that the contribution of forces produced by the spring back phenomenon in the vertical component decreases appreciably with the advance of the cutting tool tooth. The second factor is that the cutting forces generated during the machining process are added in the negative component of the vertical axis.

Horizontal force steady rises because of the horizontal contributions given during the simulation of the spring back and cutting forces. The horizontal cutting forces are primarily increased because of the increase in chip thickness as the tool rotates. Subsequently, the forces coming from the spring back increase their contribution in the horizontal axis while the cutting force contribution becomes less relevant with the advance of the cutter 
tooth. Figure 19 visualises the global machining forces collected for the cutting tool edge radius of $10 \mu \mathrm{m}, 20 \mu \mathrm{m}, 40 \mu \mathrm{m}$, and $50 \mu \mathrm{m}$, which is the subject of the above statements.

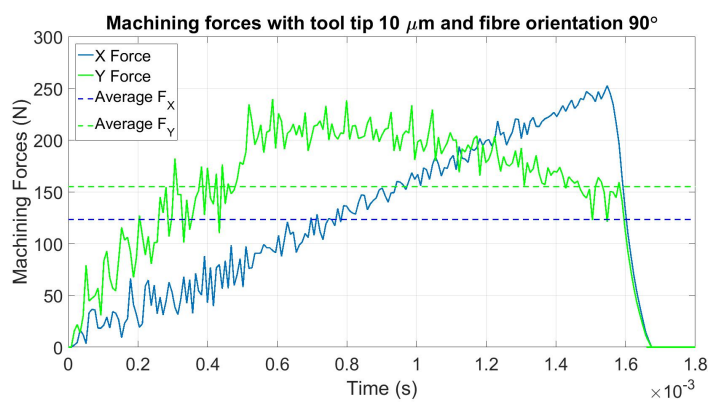

(a)

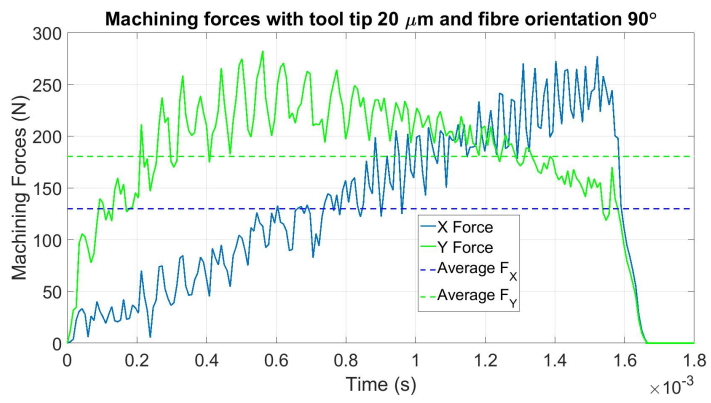

(b)

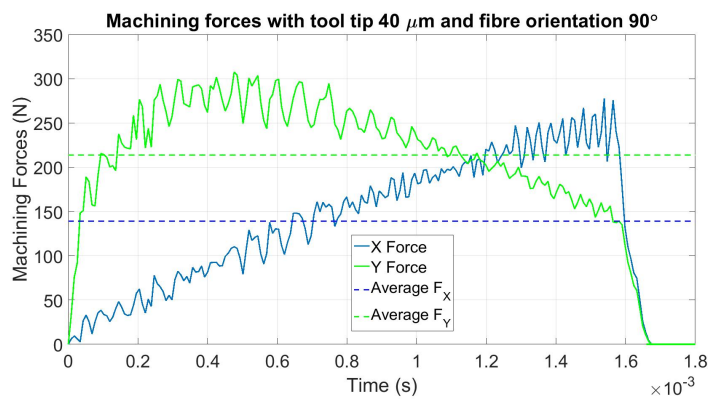

(c)

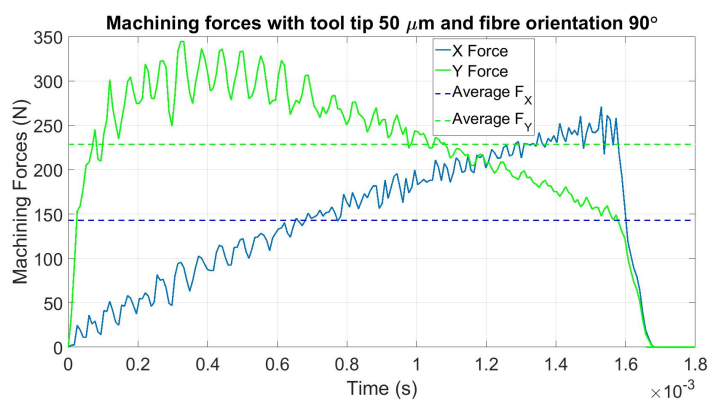

(d)

Figure 19. $F_{X}$ and $F_{Y}$ forces simulated in laminates with a fibre orientation of $90^{\circ}$ and tool edge radius of (a) $10 \mu \mathrm{m}$, (b) $20 \mu \mathrm{m}$, (c) $40 \mu \mathrm{m}$, and (d) $50 \mu \mathrm{m}$.

Regarding the forces measured in the tooth of the cutting tool $F_{N}$ and $F_{T}$, they reach a stable level of force over which they fluctuate. Different reasons explain this trend for both investigated forces. In the case of $F_{N}$, this force is obtained as a consequence of the spring back phenomenon. Initially, a rapid force increase is observed because the penetration stiffness is high when the tool pushes the laminate in a direction parallel to the fibre. As the tool advances, the relative machining angle decreases in a range from $90^{\circ}$ to $30^{\circ}$, softening the workpiece/cutting tool contact and substantially reducing the contact 
stiffness. The level of force previously obtained is maintained due to the deeper penetration of the cutting tool tooth (with an increase in chip thickness), however this is compensated by the contact stiffness reduction when the cutting tool tooth advances. An identical mechanism occurs with the tangential forces $F_{T}$, where the cutting forces decrease with relative cutting angles lower than $90^{\circ}$. However, in this analysis, this factor is compensated by the larger amount of material removed when the simulation goes ahead. As seen in Figure 20, the reached force levels of $F_{N}$ are significantly higher than those of $F_{T}$ because each pass of the tool tooth has a small depth-of-cut.

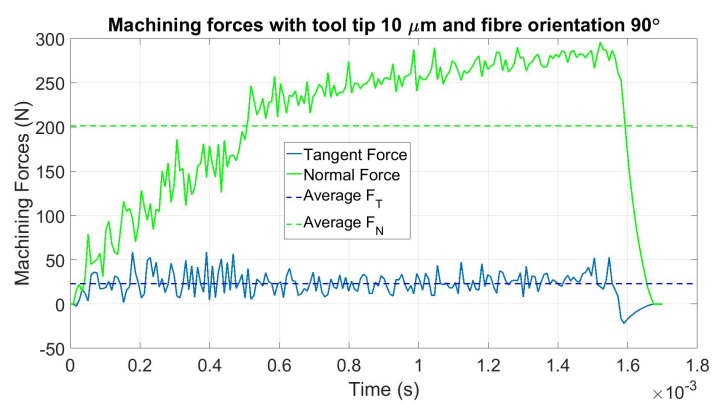

(a)

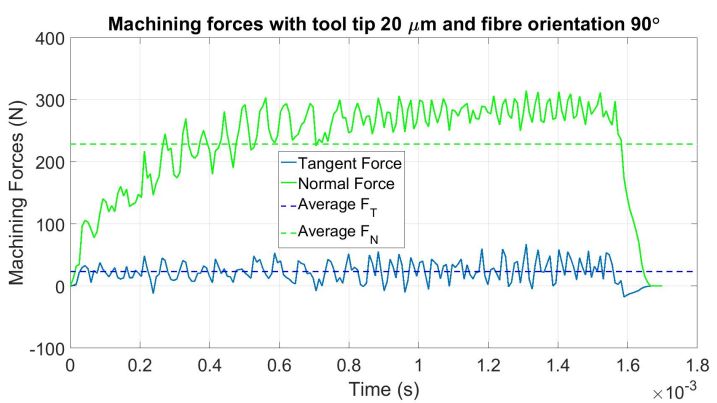

(b)

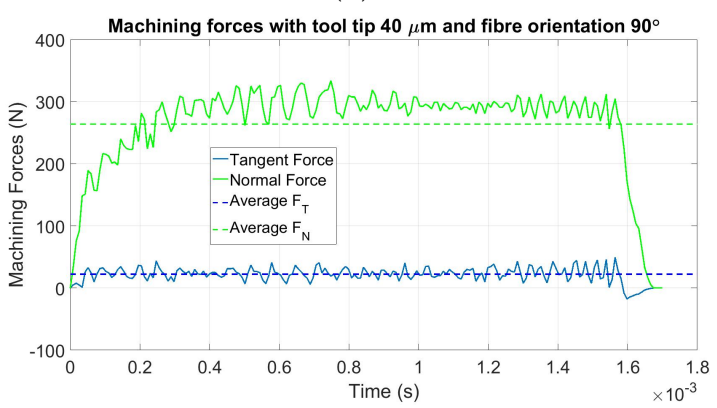

(c)

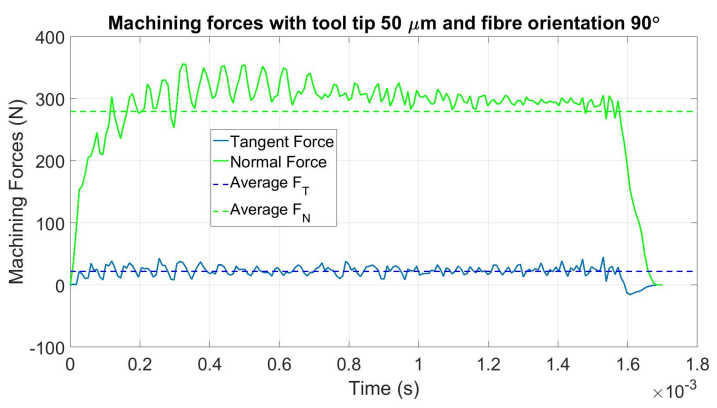

(d)

Figure 20. $F_{T}$ and $F_{N}$ forces simulated in laminates with a fibre orientation of $90^{\circ}$ and a tool edge radius of (a) $10 \mu \mathrm{m}$, (b) $20 \mu \mathrm{m}$, (c) $40 \mu \mathrm{m}$, and (d) $50 \mu \mathrm{m}$. 
The average forces simulated in this investigation highlight several assertions. The machining forces tend to experience a linear incremental increase produced by the effect of the cutting tool wear. A gradual and significant increase in the forces $F_{N}$ and $F_{Y}$ caused by tool wear was observed to increase in maximum forces of $38.79 \%$ and $47.45 \%$, respectively. This rise is less pronounced for $F_{X}$ forces, achieving a maximum increment of $16.12 \%$, while the $F_{T}$ forces do not show a significant variation due to the wear of the cutting tool. This effect is due to the increased contact area between the workpiece and the worn cutting tool. All the data obtained in the simulations performed are illustrated in Figure 21, while the force increases obtained in comparison with the forces obtained with the unworn tool with a tool edge radius of $10 \mu \mathrm{m}$, are shown in Table 6 .

Table 6. Average forces and increment percentage because of the tool wear simulated.

\begin{tabular}{ccccc}
\hline Tool Edge Radius & Average $\boldsymbol{F}_{\boldsymbol{X}}(\boldsymbol{N})$ & Average $\boldsymbol{F}_{\boldsymbol{Y}}(\boldsymbol{N})$ & Average $\boldsymbol{F}_{T}(\boldsymbol{N})$ & Average $\boldsymbol{F}_{\boldsymbol{N}}(\boldsymbol{N})$ \\
\hline $10 \mu \mathrm{m}$ & $123.17(-\%)$ & $155.04(-\%)$ & $23.01(-\%)$ & $201.26(-\%)$ \\
$20 \mu \mathrm{m}$ & $129.71(5.31 \%)$ & $180.41(16.36 \%)$ & $23.44(1.86 \%)$ & $228.45(13.51 \%)$ \\
$30 \mu \mathrm{m}$ & $135.51(10.02 \%)$ & $196.43(26.69 \%)$ & $23.62(2.65 \%)$ & $245.66(22.06 \%)$ \\
$40 \mu \mathrm{m}$ & $139.03(12.88 \%)$ & $213.74(37.85 \%)$ & $22.34(-2.92 \%)$ & $263.60(30.97 \%)$ \\
$50 \mu \mathrm{m}$ & $143.02(16.12 \%)$ & $228.62(47.45 \%)$ & $22.09(-3.99 \%)$ & $279.34(38.79 \%)$ \\
\hline
\end{tabular}

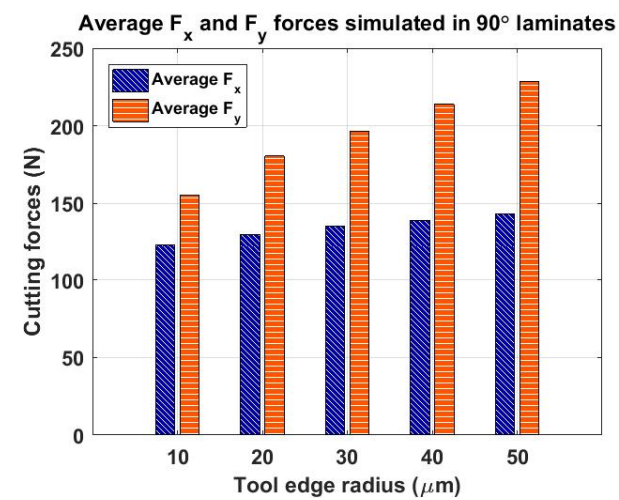

(a)

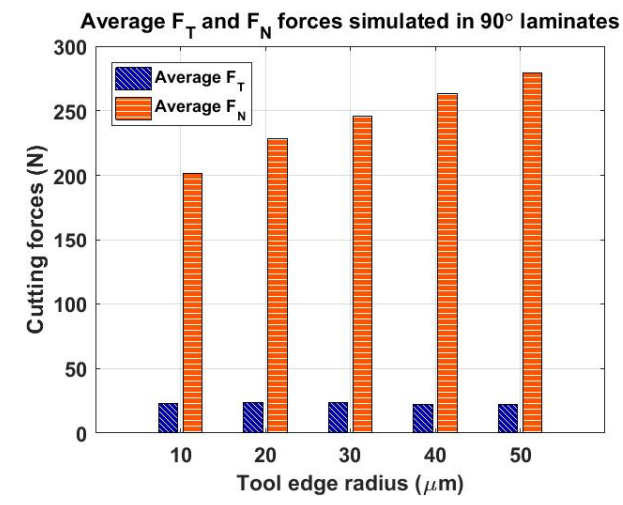

(b)

Figure 21. Representation of the average machining forces simulated with a fibre orientation of $90^{\circ}$ : (a) $F_{X}$ and $F_{Y}(\mathbf{b}) F_{T}$ and $F_{N}$.

A deeper analysis of the results simulated in $45^{\circ}$ and $90^{\circ}$ laminates yield the following conclusions. The increment of the machining forces occurs because the tool edge wear decrease the fibre cutting effectiveness. A worn tool, instead of shearing the fibres away, tends to bend the fibres, increasing the machining forces and sub-surface damage. Generally, the increment of machining forces occurs because the tool/workpiece contact area is increased. This factor increases the spring back and frictional forces. The spring back 
forces increase significantly because a bigger area of the tool penetrates inside the laminates, adding a substantial force in the normal component $\left(F_{N}\right)$. The tangential force $\left(F_{T}\right)$ changes are smaller because, despite the friction forces increasing due to contact area increments, the tangential component of the spring back forces is contrary to the frictional force. Therefore, both effects are counteracted, avoiding a clear trend in the tangential forces. Horizontal and vertical force $\left(F_{X}\right.$ and $\left.F_{Y}\right)$ increments are the result of the projections of the significant spring back force increment. In general, the increments of $F_{Y}$ caused by tool wear are more severe than the force increments observed in $F_{X}$.

\section{Conclusions}

In this research, we developed a novel study for the modelling of edge trimming of CFRP laminates using a worn cutting tool. The tool wear effect on machining forces was successfully modelled in $45^{\circ}$ and $90^{\circ}$ laminates. A composite damage algorithm based on the hybrid PuckMaximum stress criteria was used to calculate damage initiation with a linear energy-based degradation of the mechanical properties and to mimic composite behaviour. Validation of average machining forces predictions was achieved by obtaining relatively small errors (within $10 \%$ ) compared to experimental data. These predictions notably enhance the numerical results achieved in previous investigations in this matter. These improvements are obtained because of the numerical implementation of the spring back phenomenon, which adds to the simulation machining forces. Several relevant conclusions extracted from this study are summarised in the below bullet points.

- In all developed simulations, the normal forces $\left(F_{N}\right)$ simulated are much higher than the tangential forces $\left(F_{T}\right)$; meaning that spring back forces are predominant to the cutting forces in these analyses.

- The rise observed in $F_{N}, F_{X}$, and $F_{Y}$ is result of the increment of spring back forces, while $F_{T}$ keeps stable because the increment of the spring back and frictional forces is compensated for.

- Increments in $F_{Y}$ caused by tool wear were observed to be more severe than increments in $F_{X}$. Therefore, the evolution of vertical forces should be investigated to determine the appropriate timing to replace worn inserts.

- A steady increase in normal $\left(F_{N}\right)$ and vertical $\left(F_{Y}\right)$ average forces because the effect of the tool wear was observed in both studied laminates. These increments are more severe in $90^{\circ}$ laminates.

- Normal and tangential machining forces depict a steady rise in $45^{\circ}$ laminates. This happens because the range of machining relative angles from $45^{\circ}$ to $-15^{\circ}$ does not modify the spring back force significantly, nor cutting forces. Therefore, this rise is governed by the progressive increment of the depth-of-cut when the cutting tool tooth advances.

- Normal machining forces of $90^{\circ}$ laminates have an initial steep rise to later fluctuate between a stable value. In the normal force, the cutting tool tooth is pushing down the laminate parallel to the fibre, finding a high contact rigidity that decreases significantly when the machining relative angle is far from this $90^{\circ}$.

Note that interesting technical applications could be achieved using the FE model developed in this investigation. For instance, it could detect the point where the tool should be replaced, thus saving manufacturing time and optimising the tool's use. Apart from this point, another analysis could be developed using this framework. The FE model developed in this research offers an excellent capability to analyse how other relevant cutting parameters such as feed rate, cutting speed, fibre orientation, or rake and relief angles affect the machining forces. Therefore, this FE model or similar FE models can be used in oncoming composite milling investigations to quantify the effects of cutting edge rounding and CFRP machining failure mechanisms.

Author Contributions: Conceptualization, J.L.C.-S. and K.K.; methodology, F.C.-M. and N.D.; software, F.C.-M.; validation, N.D. and F.C.-M. formal analysis, N.D.; investigation, F.C.-M.; resources, N.D. and K.K.; data curation, N.D.; writing-original draft preparation, F.C.-M.; writing-review 
and editing, F.C.-M.; visualization, F.C.-M.; supervision, J.L.C.-S., K.K. and V.A.P.; project administration, F.C.-M.; funding acquisition, J.L.C.-S. and K.K. All authors have read and agreed to the published version of the manuscript.

Funding: This research was funded by EPSRC grant number EP/L016257/1. The APC was funded by The University of Sheffield.

Institutional Review Board Statement: Not applicable.

Informed Consent Statement: Not applicable.

Data Availability Statement: The data presented in this study are available on request from the corresponding author. The data are not publicly available due to intellectual property reasons.

Conflicts of Interest: The authors declare no conflict of interest.

\section{References}

1. Othman, R.; Ismail, N.I.; Pahmi, M.A.A.H.; Basri, M.H.M.; Sharudin, H.; Hemdi, A.R. Application of Carbon Fiber Reinforced Plastics in Automotive Industry: A Review. J. Mech. Manuf. 2019, 1, 144-154.

2. Hu, Y.; Xiao, Y.; Shang, W.; Zhang, J. Effect of fibre direction and stacking sequence on dynamic impact performance of composite bicycle frame. Int. J. Crashworthiness 2017, 22, 556-564. [CrossRef]

3. Yang, X.D.; Gu, F.; Chen, X. Performance Improvement of Carbon Fiber Reinforced Epoxy Composite Sports Equipment. Key Eng. Mater. 2021, 871, 228-233. [CrossRef]

4. Rubino, F.; Nisticò, A.; Tucci, F.; Carlone, P. Marine Application of Fiber Reinforced Composites: A Review. J. Mar. Sci. Eng. 2020, 8, 26. [CrossRef]

5. Zhu, L.; Li, N.; Childs, P. Light-weighting in aerospace component and system design. Propuls. Power Res. 2018, 7, 103-119. [CrossRef]

6. Pandian, G.; Pecht, M.; Zio, E.; Hodkiewicz, M. Data-driven reliability analysis of Boeing 787 Dreamliner. Chin. J. Aeronaut. 2020, 33, 1969-1979. [CrossRef]

7. Criado, V.; Feito, N.; Cantero Guisández, J.L.; Díaz-Álvarez, J. A new cutting device design to study the orthogonal cutting of CFRP laminates at different cutting speeds. Materials 2019, 12, 4074, [CrossRef]

8. Anan, R.; Matsuoka, H.; Ono, H.; Ryu, T.; Nakae, T.; Shuto, S.; Watanabe, S.; Sato, Y. Effects of Cutting Speed, Cutting Fluid, and Carbon Fiber Orientation on Cutting of CFRP during Turning. Key Eng. Mater. 2017, 740, 133-138. [CrossRef]

9. An, Q.; Zou, F.; Cai, X.; Gao, M.; Chen, M. Experimental investigation on the machinability of CFRP/Invar36 hybrid co-cured material in turning operations. Int. J. Adv. Manuf. Technol. 2020, 107, 3715-3726. [CrossRef]

10. Rao, Y.S.; Mohan, N.S.; Shetty, N.; Shivamurthy, B. Drilling and structural property study of multi-layered fiber and fabric reinforced polymer composite-A review. Mater. Manuf. Process. 2019, 34, 1549-1579. [CrossRef]

11. Jiao, A.; Zhang, G.; Liu, B.; Liu, W. Prediction of manufacturing quality of holes based on a bp neural network. Appl. Sci. 2020, 10, 2108, [CrossRef]

12. Lee, J.H.; Ge, J.C.; Song, J.H. Study on burr formation and toolwear in drilling cfrp and its hybrid composites. Appl. Sci. 2021, 11, 384, [CrossRef]

13. Wang, C.; Liu, G.; An, Q.; Chen, M. Occurrence and formation mechanism of surface cavity defects during orthogonal milling of CFRP laminates. Compos. Part B Eng. 2017, 109, 10-22. [CrossRef]

14. Chen, T.; Wang, D.; Gao, F.; Liu, X. Experimental study on milling CFRP with staggered PCD cutter. Appl. Sci. 2017, 7, 934, [CrossRef]

15. Chen, T.; Gao, F.; Li, S.; Liu, X. The comparative study on cutting performance of different-structure milling cutters in machining CFRP. Appl. Sci. 2018, 8, 1353, [CrossRef]

16. Nixon-Pearson, O.J.; Hallett, S.R. An experimental investigation into quasi-static and fatigue damage development in bolted-hole specimens. Compos. Part B Eng. 2015, 77, 462-473. [CrossRef]

17. Haddad, M.; Zitoune, R.; Eyma, F.; Castanie, B. Study of the surface defects and dust generated during trimming of CFRP: Influence of tool geometry, machining parameters and cutting speed range. Compos. Part A Appl. Sci. Manuf. 2014, 66, 142-154. [CrossRef]

18. Prakash, R.; Krishnaraj, V.; Zitoune, R.; Sheikh-Ahmad, J. High-Speed Edge Trimming of CFRP and Online Monitoring of Performance of Router Tools Using Acoustic Emission. Materials 2016, 9, 798. [CrossRef]

19. Nguyen-Dinh, N.; Zitoune, R.; Bouvet, C.; Leroux, S. Surface integrity while trimming of composite structures: X-ray tomography analysis. Compos. Struct. 2019, 210, 735-746. [CrossRef]

20. Nguyen-Dinh, N.; Hejjaji, A.; Zitoune, R.; Bouvet, C.; Salem, M. New tool for reduction of harmful particulate dispersion and to improve machining quality when trimming carbon/epoxy composites. Compos. Part A Appl. Sci. Manuf. 2020, 131, 105806. [CrossRef]

21. Nguyen-Dinh, N.; Bouvet, C.; Zitoune, R. Influence of machining damage generated during trimming of CFRP composite on the compressive strength. J. Compos. Mater. 2020, 54, 1413-1430. [CrossRef] 
22. Khosravani, M.R.; Anders, D.; Weinberg, K. Influence of strain rate on fracture behavior of sandwich composite T-joints. Eur. J. Mech. A/Solids 2019, 78, 103821. [CrossRef]

23. Liu, K.; Liu, J.L.; Wang, Z. A damage threshold prediction model of CFRP panel by hail impact based on delamination mechanism. Eng. Fract. Mech. 2020, 239, 107282. [CrossRef]

24. Cepero-Mejías, F.; Curiel-Sosa, J.; Blázquez, A.; Yu, T.; Kerrigan, K.; Phadnis, V. Review of recent developments and induced damage assessment in the modelling of the machining of long fibre reinforced polymer composites. Compos. Struct. 2020, 240, 112006. [CrossRef]

25. Zenia, S.; Ben Ayed, L.; Nouari, M.; Delamézière, A. Numerical analysis of the interaction between the cutting forces, induced cutting damage, and machining parameters of CFRP composites. Int. J. Adv. Manuf. Technol. 2015, 78, 465-480. [CrossRef]

26. Wang, D.; He, X.; Xu, Z.; Jiao, W.; Yang, F.; Jiang, L.; Li, L.; Liu, W.; Wang, R. Study on Damage Evaluation and Machinability of UD-CFRP for the Orthogonal Cutting Operation Element Method. Materials 2017, 10, 204. [CrossRef]

27. Cepero-Mejías, F.; Curiel-Sosa, J.; Kerrigan, K.; Phadnis, V. Chip formation in machining of unidirectional carbon fibre reinforced polymer laminates: FEM based assessment. Procedia CIRP 2019, 85, 302-307. [CrossRef]

28. Shetty, N.; Shahabaz, S.M.; Sharma, S.S.; Divakara Shetty, S. A review on finite element method for machining of composite materials. Compos. Struct. 2017, 176, 790-802. [CrossRef]

29. Phadnis, V.A.; Makhdum, F.; Roy, A.; Silberschmidt, V.V. Drilling in carbon/epoxy composites: Experimental investigations and finite element implementation. Compos. Part A Appl. Sci. Manuf. 2013, 47, 41-51. [CrossRef]

30. Feito, N.; López-Puente, J.; Santiuste, C.; Miguélez, M.H. Numerical prediction of delamination in CFRP drilling. Compos. Struct. 2014, 108, 677-683. [CrossRef]

31. Isbilir, O.; Ghassemieh, E. Numerical investigation of the effects of drill geometry on drilling induced delamination of carbon fiber reinforced composites. Compos. Struct. 2013, 105, 126-133. [CrossRef]

32. Feito, N.; Díaz-Álvarez, J.; López-Puente, J.; Miguelez, M. Experimental and numerical analysis of step drill bit performance when drilling woven CFRPs. Compos. Struct. 2018, 184, 1147-1155. [CrossRef]

33. Díaz-Álvarez, A.; Díaz-Álvarez, J.; Santiuste, C.; Miguélez, M. Experimental and numerical analysis of the influence of drill point angle when drilling biocomposites. Compos. Struct. 2019, 209, 700-709. [CrossRef]

34. Jin, X.; Altintas, Y. Prediction of micro-milling forces with finite element method. J. Mater. Process. Technol. 2012, $212,542-552$. [CrossRef]

35. Nasr, M.N.; Ammar, M.M. An Evaluation of Different Damage Models when Simulating the Cutting Process Using FEM. Procedia CIRP 2017, 58, 134-139. [CrossRef]

36. Wojciechowski, S.; Matuszak, M.; Powałka, B.; Madajewski, M.; Maruda, R.W.; Królczyk, G.M. Prediction of cutting forces during micro end milling considering chip thickness accumulation. Int. J. Mach. Tools Manuf. 2019, 147, 103466, [CrossRef]

37. Gao, Y.; Ko, J.H.; Lee, H.P. 3D coupled Eulerian-Lagrangian finite element analysis of end milling. Int. J. Adv. Manuf. Technol. 2018, 98, 849-857. [CrossRef]

38. Ghafarizadeh, S.; Chatelain, J.F.; Lebrun, G. Finite element analysis of surface milling of carbon fiber-reinforced composites. Int. J. Adv. Manuf. Technol. 2016, 87, 399-409. [CrossRef]

39. Curiel-sosa, J.L.; Tafazzolimoghaddam, B.; Zhang, C. Modelling fracture and delamination in composite laminates: Energy release rate and interface stress. Compos. Struct. 2018, 189, 641-647. [CrossRef]

40. Wang, C.; Wen, L.; Ming, W.; An, Q.; Chen, M. Experimental study on effects of fiber cutting angle in milling of high-strength unidirectional carbon fiber-reinforced polymer laminates. Proc. Inst. Mech. Eng. Part J. Eng. Manuf. 2018, 232, 1813-1824. [CrossRef]

41. Duboust, N.; Watson, M.; Marshall, M.; O’Donnel, G.E.; Kerrigan, K. Towards intelligent CFRP composite machining: Surface analysis methods and statistical data analysis of machined fibre laminate surfaces. Proc. Inst. Mech. Eng. Part J. Eng. Manuf. 2020. [CrossRef]

42. M'Saoubi, R.; Axinte, D.; Leung, S.; Nobel, C.; Attia, H.; Kappmeyer, G.; Engin, S.; Sim, W.M. Manufacturing Technology High performance cutting of advanced aerospace alloys and composite materials. CIRP Ann. Manuf. Technol. 2015, 64, 557-580. [CrossRef]

43. Cepero-Mejías, F.; Curiel-Sosa, J.L.; Zhang, C.; Phadnis, V.A. Effect of cutter geometry on machining induced damage in orthogonal cutting of UD polymer composites: FE study. Compos. Struct. 2019, 214, 439-450. [CrossRef]

44. Duboust, N.; Pinna, C.; Ghadbeigi, H.; Ayvar-Soberanis, S.; Phadnis, V.A.; Collis, A.; Kerrigan, K. 2D and 3D Finite Element Models for the Edge Trimming of CFRP. In Proceedings of the 16th CIRP Conference on Modelling of Machining Operations, Burgundy, France, 15-16 June 2017; Volume 58, [CrossRef]

45. Chardon, G.; Klinkova, O.; Rech, J.; Drapier, S.; Bergheau, J.M. Characterization of friction properties at the work material/cutting tool interface during the machining of randomly structured carbon fibers reinforced polymer with Poly Crystalline Diamond tool under dry conditions. Tribol. Int. 2015, 81, 300-308. [CrossRef]

46. Lapczyk, I.; Hurtado, J.A. Progressive damage modeling in fiber-reinforced materials. Compos. Part A Appl. Sci. Manuf. 2007, 38, 2333-2341. [CrossRef]

47. Jones, R.M. Mechanics of Composite Materials, 2nd ed.; Taylor \& Francis: Blacksburg, VA, USA, 1995; p. 519. 
48. Cepero-Mejías, F.; Phadnis, V.A.; Curiel-sosa, J.L. Machining induced damage in orthogonal cutting of UD composites: FEA based assessment of Hashin and Puck criteria. In Proceedings of the 17th CIRP Conference on Modelling of Machining Operations, Sheffield, UK, 13-14 June 2019; Volume 82, pp. 332-337. [CrossRef]

49. Hinton, M.J.; Kaddour, A.S.; Soden, P.D. A comparison of the predictive capabilities of current failure theories for composite laminates, judged against experimental evidence. Compos. Sci. Technol. 2002, 62, 1725-1797. [CrossRef]

50. Puck, A.; Schurmann, H. Failure Analysis of Frp Laminates by Means of Physically Based Phenomenological Models* Compos. Sci. Technol. 1998, 3538, 1633-1662. [CrossRef]

51. Bažant, Z.P.; Oh, B.H. Crack band theory for fracture of concrete. Matér. Constr. 1983, 16, 155-177. [CrossRef]

52. Zhang, C.; Duodu, E.A.; Gu, J. Finite element modeling of damage development in cross-ply composite laminates subjected to low velocity impact. Compos. Struct. 2017, 173, 219-227. [CrossRef]

53. Lasri, L.; Nouari, M.; El Mansori, M. Modelling of chip separation in machining unidirectional FRP composites by stiffness degradation concept. Compos. Sci. Technol. 2009, 69, 684-692. [CrossRef]

54. Paris Carballo, F.; Cañas, J.; Marín, J. Introduccióon al Análisis y Diseño con Materiales Compuestos; Universidad de Sevilla, Escuela Técnica Superior de Ingenieros: Sevilla, Spain, 2008; p. 241.

55. Santiuste, C.; Soldani, X.; Miguélez, M.H. Machining FEM model of long fiber composites for aeronautical components. Compos. Struct. 2010, 92, 691-698. [CrossRef] 